\title{
Exploring Relationships Between L2 Chinese Character Writing and Reading Acquisition From Embodied Cognitive Perspectives: Evidence From HSK Big Data
}

\author{
Xingsan Chai ${ }^{\star \dagger}$ and Mingzhu Ma ${ }^{\dagger}$ \\ Institute on Educational Policy and Evaluation of International Students, Beijing Language and Culture University, Beijing, \\ China
}

OPEN ACCESS

Edited by:

Yang Zhang,

University of Minnesota Health Twin

Cities, United States

Reviewed by:

Zhenguang Cai,

The Chinese University of Hong Kong,

Hong Kong SAR, China

Haiwei Zhang,

Minzu University of China, China

*Correspondence:

Xingsan Chai

cxs66@blcu.edu.cn

${ }^{t}$ These authors have contributed equally to this work and share first

authorship

Specialty section:

This article was submitted to Language Sciences, a section of the journal

Frontiers in Psychology

Received: 18 September 2021 Accepted: 23 December 2021

Published: 21 February 2022

Citation:

Chai X and Ma M (2022) Exploring Relationships Between L2 Chinese

Character Writing and Reading Acquisition From Embodied Cognitive Perspectives: Evidence From HSK Big Data. Front. Psychol. 12:779190. doi: 10.3389/fpsyg.2021.779190
Chinese characters are central to understanding how learners learn to read a logographic script. However, researchers know little about the role of character writing in reading Chinese as a second language (CSL). Unlike an alphabetic script, a Chinese character symbol transmits semantic information and is a cultural icon bridging embodied experience and text meaning. As a unique embodied practice, writing by hand contributes to cognitive processing in Chinese reading. Therefore, it is essential to clarify how Chinese character writing (bodily activity), language distance (past language usage), and cultural background (bodily coupling with the environment) influence CSL reading proficiency. Based on extant research on L2 reading acquisition and strength of key theoretical perspectives of embodied cognition theory (ECT), this study tested a regression model for CSL reading involving individual-level factors (Chinese character writing proficiency [CCWP]) and group-level predictors (language distance and cultural background). This study collected big data in a sample of 74,362 CSL learners with 67 diverse L1s. Results of hierarchical linear modeling showed a significant effect of CCWP and significant language distance $\times$ CCWP interaction effect on reading proficiency; however, cultural background $\times$ CCWP interaction effect was not significant. These results conform to the ECT and indicate that bodily activity, past language usage, and cultural background aided reading. CCWP may benefit from withstanding the negative transfer from L1s. Furthermore, CCWP and cultural background are not synergistic predictors of reading. This study may open novel avenues for explorations of CSL reading development.

Keywords: Chinese as a second language (CSL) reading, Chinese character writing, Sinosphere, language distance, embodied cognition theory

\section{INTRODUCTION}

Reading and writing are inextricably linked. Chinese characters, regarded as most complicated visual scripts (Chang et al., 2018), are central to our understanding of how learners learn to read a logographic script (Tan et al., 2005a,b; McBride, 2016; Yin and Zhang, 2021). Given wide differences between alphabetic and logographic scripts, learning to read and write Chinese characters is one of the main challenges and a real problem for CSL beginners who are non-native Chinese speakers (Allen, 2008; Ye, 2013; Li, 2020). 
In literacy education, the increasing use of electronic media and devices gives rise to a spirited debate centering on the role of Chinese characters: does Chinese reading depend on character writing $^{1}$ (Tan et al., 2005b; Bi et al., 2009)? Is it necessary to learn Chinese character writing (Allen, 2008; Lam and McBride, 2018; Zhou et al., 2020)? When is the best time to start learning Chinese characters? (Ye, 2013; Knell and West, 2017). Over the past two decades, many cross-disciplinary scholars have attempted to solve these problems. These studies mainly focused on character recognition (e.g., Siok and Fletcher, 2001; Liao et al., 2008; Guan and Fraundorf, 2020; Jiang et al., 2020; Zhang H. et al., 2020; Zimmer and Fischer, 2020; Guan et al., 2021), without considering the role of the embodiment of handwriting, which is deemed essential to the embodied cognition theory (ECT). Specifically, the ECT underlines the interaction among perception, action, body, and the environment (Barsalou, 2008). This theory also offers a novel perspective on relationships between language and cognition (that is, the physical body and embodied experience are the origins of cognition), setting it apart from the modular view of linguistic nativism, linguistic determinism, and linguistic relativity, which treats language and cognition as distinct and independent systems.

Some recent studies have established and adopted a largescale character handwriting database to examine relationships between Chinese character writing and reading. Of these, Wang et al. (2020) collected 200 handwriting characters from 203 native Chinese speakers with their writing latencies, durations, and accuracies. They used this database to explore influential factors of Chinese character amnesia (Huang et al., 2021b) and then further investigated the role of lexical characteristics and individual differences in relationships among tip of the pen (TOP), character amnesia, and partial orthographic access in TOP states (Huang et al., 2021a). However, researchers have used different production protocols and measurements of Chinese character writing and reading. For example, Wong (2018) measured writing fluency using a character copying task with restricted time. In the research of Li et al. (2019), writing was assessed with a dictation task.

This study aimed to examine the role of Chinese handwriting in reading acquisition through big data from a national CSL proficiency test, Hanyu Shuiping Kaoshi (HSK). The primary objective was to investigate how three embodiment factors of a Chinese character, Chinese character writing (bodily activity), language distance (past language usage), and cultural background (bodily coupling with the environment), may contribute to individual differences in CSL reading proficiency. By highlighting the role of character writing in CSL reading acquisition, we hope to contribute to the existing literature for a better understanding of the multifaceted and embodied features of CSL reading acquisition and provide support to the theoretical perspectives of ECT.

\footnotetext{
${ }^{1}$ Writing is the process of representing a language with written symbols to communicate thoughts and ideas in a readable form, while handwriting emphasize the process of scripts written by hand. We use the phrase "Chinese character writing" or "handwriting" to refer to the action of producing Chinese characters by hand from memory.
}

\section{Overview of Chinese Character Research Orthographic Knowledge of Chinese Characters}

Researchers generally have acknowledged that sufficient orthographic knowledge benefits the processing of word spelling and reading comprehension (Perfetti and Hart, 2002; Ehri, 2005, 2014; Koda, 2007). However, as a morpheme-syllabic writing system, the orthography of Chinese is noticeably different from grapheme-phoneme writing systems such as English. This difference becomes one of the main challenges in learning Chinese (Shen, 2010; Hsiao et al., 2015; Zhang and Reilly, 2015; $\mathrm{Li}, 2020$ ). There are two main difficulties that may be caused by this L1-L2 orthographic variance in CSL acquisition.

The first difficulty is due to complicated components of Chinese orthography, which requires lots of cognitive effort to decode, memorize, and distinguish (Qian et al., 2018). Chinese characters can be roughly classified into two categories: compound and integral (Wang et al., 2003; Shen and Ke, 2007; Du, 2015). In general, an integral character has only one radical on its own, and a compound character contains at least two or more radicals. The orthography of almost all Chinese characters consists of three elements: stroke, radical, and whole character (Shen and Ke, 2007). Usually, several strokes constitute a radical and several radicals form a character. Statistically, in modern Chinese, 214 radicals with 32 strokes that convey both sematic and pronounceable information appear in about $80 \%$ of 7,000 frequent Chinese characters (McNaughton and Ying, 1999; Chinese Language Committee, 2009).

The second difficulty is the weak correspondence between form and pronunciation of Chinese characters (Shen, 2005; Sung and $\mathrm{Wu}, 2011)$. Especially, majority of Chinese characters are homophones. For example, the phonogram “蛛” (pronounced

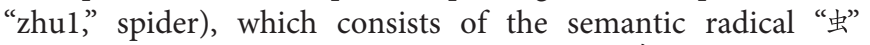
meaning "insect," and the phonetic radical “朱” (pronounced "zhul") (the numbers are for indicating tones). Likewise, “珠," “株,”“荣," and “侏” are all pronounced “zhul” based on their phonetic radical “侏." However, the connection among pronunciation, meaning, and character form is not always regular. In other words, it is diverse for the correspondence between the pronunciation of a phonogram and its combination of radicals. For instance, “殊” (pronounced "shu1," different) is not dependent on its phonetic radical “佅” (zhul) or its semantic radical “多” meaning “evil." An indexical hypothesis (Glenberg and Robertson, 1999) claims that the most important language comprehension process is indexing of words or scripts to corresponding objects or mental representations. Together, these examples and studies indicate that understanding the underlying schema of Chinese characters could contribute to further Chinese reading comprehension of learners.

In summary, Chinese seems more linguistically complex than other languages might be on account of the unique combination rules of character orthography. However, the complicated features are almost certainly results of the historical evolution of the Chinese language for over thousands of years. As a basic unit of the Chinese language, character, which heavily carries culture, is a semiotic tool to communicate and a medium of cognition and thought. 


\section{Embodiment of Chinese Characters}

Since the 1980s, the idea of embodiment has received increasing emphasis in cognitive sciences. According to the ECT, the medium through which one knows the world is the "body" (e.g., Clark, 1997; Lakoff and Johnson, 1999; Glenberg and Robertson, 2000; Streeck et al., 2011; Glenberg and Gallese, 2012; Wilson and Golonka, 2013). This "body" not only refers to one's physical organisms but also bodily contact with the world (Inui, 2006). Namely, cognition is assumed to be grounded in embodied experience (embracing bodily activity and perceptual experience) and context. So far, scholars have a different understanding of embodiment. Based on previous literature, the implications of the embodiment of Chinese characters can be discussed in three aspects.

First, handwriting is an embodied activity. The ECT claims that cognitive processing is associated with the particularity of one's physiological body (Shapiro, 2007; Streeck et al., 2011; Glenberg and Gallese, 2012). In other words, bodily activity might be a way of knowing. It has previously been observed that the perceptuo-motor process of bodily activity offers information and potentially influences the construction of knowledge (Streeck et al., 2011; Lawrence, 2012). For example, study of Strati (2007) described how a building worker skillfully walked on a roof using the tactile experience of his feet.

Thus, a handwritten script is "an imprint of action" (Longcamp et al., 2006). Writing by hand is a direct way by which bodily movements can interact with cognitive processing. In addition, handwriting mobilizes perceptuo-motor processing (Addy, 1996), and then the perception during writing contributes to cognitive processing (Longcamp et al., 2003; Tan et al., 2005b; James, 2017). Interestingly, brain neuroimaging research has found that some specific Brodmann's areas were strongly activated for Chinese characters (Tan et al., 2001, 2005a; Hu et al., 2018). The findings from these studies suggest that the processing Chinese characters may be related to the experience of bodily activity. If so, handwriting, as an embodied action, might contribute to the cognitive processing of characters.

Second, learning a new language is learning a new conceptual system. Traditional dualism claimed that a physical substance (mind) had no bearing on a mental substance (body). Unlike the traditional view, the ECT supports the view that the experienced sensations and perceptions in the past are still work on one's cognitive processing in the moment (Lakoff and Johnson, 1980). In short, an embodied experience might shape one's way of thinking. Couched in the ECT framework, Lakoff and Johnson (1980) proposed that the way one conceptualizes the world is metaphorical. Likewise, there is a strong possibility that language is metaphorical. Therefore, to learn a new language ${ }^{2}$ is likely to learn a new system of metaphors and conceptions apart from language features. Research has also shown that comprehension cannot be devoiced from the bodily sensorymotor system (Desai et al., 2010; Emmorey et al., 2014; Slepian and Ambady, 2014). For example, through tasks on building bodily metaphor, Slepian and Ambady (2014) found interactions

\footnotetext{
${ }^{2}$ This study focuses on Chinese characters of Chinese writing systems. For clarity, the term "language" in this article mainly refers to written language.
}

among sensorimotor schema, comprehension and estimation, and abstract conception in reading.

Chinese, to some extent, is a representation of the ECT, with enormous metaphors involving embodied experience. Although simplification results in weaker link among radicals, the Chinese written language still represents the linguistic, psychological, and cultural features of the Chinese nation (Pae, 2020). According to Quinn (1987), a cultural model was critical for social members' understanding of the world and their behavior. Cultural models underlying the conceptualization of Chinese characters reflect culture-specific concepts constructed in Chinese context. So far, researchers have proven the effect of past language usage of bilinguals on cognitive categorization in several conceptual domains, such as speech, gestures, memory for motion, and posture (Brown and Gullberg, 2008, 2011; Filipović, 2011; Smithson and Nicoladis, 2013), objects and substances (Cook et al., 2006; Pavlenko and Malt, 2011), emotions (Pavlenko and Driagina, 2007), motion events (Bylund et al., 2013; Park, 2020), and event construals (Wang and Wei, 2019). Moreover, behavioral and event-related potential (ERP) research has found that various language speakers have different ways of perceiving and conceptualizing the world (Liu et al., 2010; Jared et al., 2013; Wang et al., 2018). For example, Liu et al. (2010) investigated English and Mandarin speakers through category judgment tasks. English speakers showed larger N300 and N400 ERP component differences. In contrast, Chinese speakers showed no such differences in processing atypical and typical items (e.g., to judge the membership of "train" in English or huo3che1 “火车” in Chinese [atypical] and "car" in English or jiao4che1 “轿车” in Chinese [typical] pictorial exemplars of a category "vehicle" in English or che1 "车" in Chinese). The researchers further found that the Chinese speakers elicited moderate N300 and N400 effects on Chinese orthographically transparent items (e.g., the radical "bug” chong2 “虫” in character for the noun “butterfly” hu2die2 “蝴蝶”), while the English speakers showed such ERP effects on English morphologically transparent items (e.g., catfish). These findings indicate dramatic differences in the English and Chinese speakers' processing of category judgments.

Therefore, one of the essential preconditions for understanding a script or a word is to underlie its metaphors and conceptions. If not, it may cause misunderstanding. Carrying over “愁” exemplifies the metaphor of Chinese characters. The metaphor “愁” originated from a Chinese schema that autumn (“秋”) is in one's heart (“心”). In detail, “心” traditionally represents the physical heart and is the core of mind, thought, and mood [see Yu (2009) for more detailed explanations]. In Chinese culture, autumn is often a metaphor for mixed emotions of happiness of the harvest and sadness of the forthcoming desolate scene. Thus, “愁” generally means a complicated feeling of happiness, worry, solitude, and sadness. Compared to the integral characters stated before, “愁” is beyond simply describing the schema of concrete objects. All of these language idioms or conventions represent the perception and conceptualization of Chinese people in daily life.

Third, cultural background influences cognition of Chinese characters. The ECT believes that interactive relationships exist among our mind, action, body, and context 
(Lakoff and Johnson, 1980, 1999; Hutchins, 1995; Barsalou, 2008; Spackman and Yanchar, 2014).

In the first place, the development of Chinese characters is embedded in culture and history, and, in turn, characters that carry cultural and linguistic information influence surrounding regions. Historically, Chinese characters were cornerstones of East Asian culture development. Characters documented Chinese culture and then spread throughout other regions for millennia. These regions are considered as a cultural sphere, Sinosphere (also known as the East Asian cultural sphere, Chinese cultural sphere, or Sinic/Sinitic world). On the one hand, there are notable linguistic similarities among Sinosphere languages (Matisoff, 1973, 2001; Enfield, 2011; Brunelle and Kirby, 2016). On the other hand, Sinosphere regions, such as Japan, Korea, and Vietnam, share similar conceptions, which can reflect in Chinese characters.

In the second place, Chinese characters acquisition is affected by bilingual learners' L1 context. Contextual factors affect and constitute cognition. ERP research has found that bilinguals' cultural context impacts their semantic (Jared et al., 2013) and conceptual representations (Berkes et al., 2018) in lexical access. To elaborate, we continue with the example “心” (heart). Matisoff (1986) discussed the concept of heart and mind in Southeast Asian languages with a comparative perspective in English. The research found that many Sinosphere languages prefer to describe psychological phenomena using metaphors of a bodily organ. For Chinese characters, radical usage, which represents bodily organs, like “心” (heart), gives morpheme a psychological allusion. As mentioned above, the Chinese "heart" covers the meaning of both heart and mind, regarded as the center of both emotion and mood. However, like other European languages, English concepts of the heart are separated from the mind. This difference reflects a culturally specific concept developed in the Anglo-Saxon context (Wierzbicka, 1989, 1992; quoted in $\mathrm{Yu}, 2009$ ). Therefore, individuals, especially bilinguals (Jared et al., 2013; Berkes et al., 2018; Wang and Wei, 2019), with different L1 sociocultural backgrounds are likely to have different cognitions for characters.

\section{Research on Chinese Character Writing and Reading Comprehension ${ }^{3}$ The Role of Chinese Characters in Reading Comprehension}

The role of Chinese characters in reading has received increased attention across a number of disciplines in recent years. Unlike an alphabetic language, the orthographic form of Chinese characters is more effective than phonological representations in reading comprehension because of weak regular corresponding rules between the form and phonology of characters (Xu et al., 2013).

\footnotetext{
${ }^{3}$ Note the difference between the phrases "Chinese character reading" and "Chinese reading (comprehension)." The former refers to recognizing a single character without passage processing, while the latter requires readers to integrate the information of characters into words and sentences in a passage, and then understand the main idea of the passage. Chinese reading (comprehension) involves more advanced and complicated cognitive processing (e.g., understanding, memorization, interpretation, and reasoning) than character reading. This study focused on Chinese reading (comprehension).
}

Some research has investigated the role of characters by stroke (e.g., Zhang, 2014; Chang et al., 2015; Dall et al., 2021), pinyin (e.g., Zhang et al., 2019; Xiao et al., 2020; Ju et al., 2021), character copy skills (e.g., Ye et al., 2021), phonological awareness (e.g., Siok and Fletcher, 2001; McBride-Chang et al., 2004; Zhang and Roberts, 2019, 2021a), morphological awareness (Nagy et al., 2002; Liu and McBride-Chang, 2010), radical awareness (Shen and Ke, 2007; Wong, 2017; Zhang and Roberts, 2019), and orthographic awareness (Siok and Fletcher, 2001; Loh et al., 2018; Tong et al., 2019; Chen et al., 2021; Zhang and Roberts, 2021a). However, differences in testing methods may lead to different results. For instance, some research (e.g., Tan et al., 2005b; Wong, 2017) employed a copy task in which materials were self-designed to the character writing ability of test participants, and the results indicated close relationships between Chinese handwriting and reading. However, other research (e.g., Zhai and Fischer-Baum, 2019) used a visual same/different judgment task on pairs of characters, and the results failed to find this significant contribution of character writing to reading.

Debates on the role of character writing have gained fresh prominence, with many arguing whether handwriting contributes to Chinese reading. There is a vast amount of research showing that strong knowledge of and skills in character writing facilitate orthographic processing in Chinese reading for children (Tan et al., 2005b; Wang et al., 2014, 2015; Chung et al., 2018; Zhang J. et al., 2020) and adults (Kuo et al., 2015; Tong and Yip, 2015; Tong et al., 2016; Zhang J. et al., 2020). However, literature has emerged that offers contradictory findings on strong effects of character writing on reading (e.g., Bi et al., 2009; Zhai and Fischer-Baum, 2019). For instance, a case study on a brain-impaired adult patient with writing deficit found no such effect of writing through reading and character writing tasks (Bi et al., 2009). Although he lost the ability to write by hand, this patient could still recognize Chinese and read it aloud. This finding displayed a clear dissociation rather than a strong relationship between Chinese writing and reading. However, conflicting results from these studies suggest the need to further investigate if CSL learners with different Chinese character writing skills also have variances in reading acquisition or, more likely, if are there factors that moderate the reading differences and, if so, what are the factors?

The importance of handwriting is now well established. While some research has been carried out on character recognition, there is very little scientific understanding of character writing. For instance, studies have found that visualorthographic knowledge can help learners more quickly and easily recognize characters (e.g., Tong and McBride-Chang, 2010; Huang et al., 2020). Nevertheless, neuroimaging studies have found that reading Chinese characters activates motorrelated zones apart from visual zones in the brain (Longcamp et al., 2003, 2005; Tan et al., 2005b; Yin and Zhang, 2021). In addition, research has also found a moderate effect of writing motor execution on deep orthographic processing (Yin et al., 2020). However, the influence of character writing on reading comprehension in CSL reading acquisition has remained unclear. 


\section{The Role of Language Learning Experience in Reading Comprehension}

Embodied cognition theory research opens an avenue for a better understanding of cognitive processing and the three elements (bodily activity, language learning experiences, and context). Reading comprehension is one of the advanced cognitive processes closely associated with linguistic knowledge and cognitive skills (Stanovich, 2000; Koda 2005a, 2007; Jeon and Yamashita, 2014). Recent L1 and L2 reading research has extensively applied the component-skills approach to reading. One much-debated question addressed by Alderson (1984) in reading research was whether L2 language knowledge (e.g., orthographic, vocabulary, and phonological knowledge) was related to reading proficiency or cognitive processing (e.g., attention, working memory and metacognitive awareness). The existing body of research on language experience suggests that prior literacy experience influences literacy development in SLA (Hamada and Koda, 2008; Koda, 2008; Tong et al., 2016), and that language learning experience benefits in the early formation of perceptual organization (Kimchi and Hadad, 2002; Yeh et al., 2003). For example, Yeh et al. (2003) investigated the effect of language learning experience on the perceived graphemic similarity of Chinese characters with two shape-sorting tasks. The results showed that Chinese and Japanese undergraduates categorized characters based on configurational structures. In contrast, Chinese illiterate adults and kindergarteners classified characters by strokes or components. However, what is not yet understood is the relationship between language experience and CSL reading comprehension.

Language distance refers to the extent of similarity or differences between two languages. In other words, language distance is a measurement of classifying languages by their linguistic features. The current understanding of language distance in SLA suggests a positive cross-linguistic influence when L1 and L2 are linguistically similar or overlapped (Sharwood Smith and Kellerman, 1986; Jarvis and Pavlenko, 2008), and negative influence more likely occurs in beginners (Odlin, 1989). This influence may happen at a conceptual level (Jarvis and Pavlenko, 2008). According to Koda's 2005a,b Transfer Facilitation Model, language transferring ability can provide top-down help for reading development and other associated abilities in another language. Because of overlaps and differences among all languages, language distance might be a main factor of the transfer.

Evidence from several studies suggest that language distance plays a moderate role in L2 reading acquisition (MelbyLervåg and Lervåg, 2011; Jeon and Yamashita, 2014). A metaanalysis research (Jeon and Yamashita, 2014) study showed that linguistically similar languages (between Indo-European L1s and L2s) were more closely related to reading comprehension than linguistically distant languages. Interestingly, in the study of Jeon and Yamashita, language distance significantly affected reading comprehension but had no moderating effects on vocabulary or grammar knowledge, thereby rejecting their hypothesis. The authors explained that observing the cross-linguistic influence might be easier at a complex variable level (e.g., reading comprehension) than at a single variable level (e.g., vocabulary and grammar). Meanwhile, Tong et al. (2016) proposed a non-native Chinese character processing (NCCP) model to explain how semantic and phonetic radical information was accessed when learners with different L1 orthographies were processing Chinese characters. In this model, L1-L2 (Chinese) orthographic distance and context modulated the activation of word identification in two language systems. However, there has been little agreement on how L1-L2 distances of learners moderate the relationship between Chinese character writing and reading comprehension.

\section{Role of Context in Reading Comprehension}

Sociocultural context is pivotal in SLA research (Vygotsky, 1978; Ellis, 2008; Green and Abutalebi, 2013; Tong et al., 2016). There are some interfaces between sociocultural theory (Vygotsky, 1978) in SLA and ECT in cognition: they both focus on the interaction between individuals and environments (Lan et al., 2015). According to the theory of Vygotsky, relationships between individuals and social context are inseparable; context and interaction with the context are two critical mediating factors in language learning (Ellis, 2008). Interacting in the social context provides essential SLA scaffolding (Vygotsky, 1978). This theory emphasizes the importance of external mediation, from which internal activity originates (Swain, 2000; Ellis, 2008). However, only few studies have investigated the role of character writing in Chinese reading acquisition based on these two crucial theoretical frameworks.

Theories on L2 reading have focused on predictors of social environment. For example, the Component Model of Reading (Joshi and Aaron, 2000, 2012) integrated individual and contextual factors. This model proposed that ecological and psychological surroundings had an impact on reading proficiency and cognitive skills. Moreover, recent bilingualism research has suggested ascribing language processing, cognitive processing, and brain organization to the experience of language learning and using and social factors surrounding this experience (Gullifer et al., 2018, 2021; Anderson et al., 2020; DeLuca et al., 2020; Tiv et al., 2020).

When it comes to Chinese characters, it is hard to overstate the importance of Sinosphere, because Sinosphere reflects the continuous improvement of East and Southeast Asian civilization around Chinese language and culture. Many previous studies have pioneered the effect of language background and compared CSL characters learners in various language contexts (Ke, 1998; Jiang, 2003; Xu, 2007; Zhang, 2008; Lin and Collins, 2012; Li et al., 2014; Ke and Chan, 2017; Tang and Chan, 2021; Zhang and Roberts, 2021b). Of these studies, Zhang (2016) compared the development of character orthographic awareness between ethnic and non-ethnic Chinese international students from Southeast Asian countries. The results failed to showed advantages of ethnic Chinese in the development of CSL character orthographic awareness but of character component and position awareness. Ke and Chan (2017) explored relationships among CSL reading strategies, L1 background, and L2 proficiency by examining participants from Chinese and non-Chinese cultural spheres. The results showed that intermediate learners with Chinese cultural background were more advantaged than the others, but this 
advantage disappeared when learners were more proficient in Chinese. These findings suggest a difference in L2 achievement in different L1 cultures.

\section{This Study}

Based on literature review, enormous research has documented the role of Chinese characters in CSL reading acquisition. However, researchers have paid little attention to the relationships between characters and reading based on the perspective of ETC and SLA from big data in a real scene. First, writing is an embodied activity, but most research on the role of Chinese characters in reading has investigated character recognition instead of character writing, and studies on character writing have adopted unofficial measurement tools or tasks to test the character writing skills of participants. Second, Chinese characters are embodied in culture and context. Although ECT frameworks have been discussed theoretically in most previous research studies, empirical evidence is still lacking. Third, since there are overlaps between the ECT and SLA, it is indispensable to employ the ECT to examine SLA issues, despite lack of previous studies. Therefore, to fill these gaps, this study focused on the following questions:

RQ1: Does character writing (i.e., bodily activity) facilitate reading?

$\mathrm{H}_{1}$ : Character writing proficiency is positively related to the reading proficiency of learners.

RQ2: How do the L1s of learners (i.e., past language experience) moderate relationships between character writing and reading?

$\mathrm{H}_{2}$ : Character writing proficiency will be more strongly associated with decrease in reading proficiency of learners when their L1s are linguistically distant to Chinese than when their L1s are more similar to Chinese.

RQ3: What role does cultural background (i.e., environment) play in the CSL reading comprehension of learners with various cultural backgrounds?

$\mathrm{H}_{3}$ : There will be an interactive effect between cultural background and handwriting. Character writing proficiency will be more strongly associated with an increase of reading proficiency of Sinosphere learners than non-Sinosphere learners.

\section{MATERIALS AND METHODS}

\section{Participants}

We made use of the subset of a large-scale database, which was gathered in 2009, containing information on 80,506 examinees who participated in the HSK test at various locations in China. A brief questionnaire collected their individual background information when examinees registered for the HSK test online. This non-mandatory survey included questions about basic demographic features of learners such as gender, country of birth, age, and mother tongue.

Next, we selected samples from the original data of 80,506 examinees. First, 4,018 participants were excluded because of missing individual information and 1,728 participants owing to their unrealistic or ambiguous answers in the questionnaire. Second, 17 participants were excluded because of the scribble of the names of their L1s. Third, the study also removed 381 participants whose age was over 80 years. The final samples consisted of 74,362 CSL learners ( $M$ age $=23.3$ years, range $=9.4-$ 79.3 years; 36,528 males and 37,834 females) without outliers (e.g., unrealistic or ambiguous answers) or missing values.

The learners spoke $67 \mathrm{~L} 1 \mathrm{~s}(M=1,109.9$ speakers per language) and came from 173 countries $(M=429.8$ speakers per country). There were 307 learners with Chinese as an L1, accounting for $0.41 \%$ of all the samples. These L1s, according to the World Atlas of Language Structures [WALS] (Dryer and Haspelmath, 2013), included about 14 language families (i.e., Afro-Asiatic, Altaic, Austro-Asiatic, Austronesian, Dravidian, Indo-European, Japanese, Kartvelian, Korean, Niger-Congo, Sino-Tibetan, TaiKadai, Turkic, and Uralic).

\section{Instruments}

\section{Hanyu Shuiping Kaoshi}

Hanyu Shuiping Kaoshi (HSK, abbreviation of Chinese pinyin: Hànyǔ Shuǐpīng Kăoshì; literally translated as Chinese Proficiency Test) is a standardized and the most widespread test for assessing the Chinese language proficiency of nonnative speakers in the world. HSK development has gone through three stages (see review by Teng, 2017 and Meyer, 2014). The HSK Testing Center of Beijing Language Institute (BLCU) designed and developed this test in 1984. Then, in 2010, China's Hanban/Confucius Institute Headquarters (i.e., Office of Chinese Language Council International) supported and reformatted the test as the New HSK. The designers kept all the three versions of HSK comparable (Hanban, 2011).

In this study, CSL reading and writing data came from the raw data of HSK (Elementary-Intermediate) $(M=50$, $S D=15)$ in 2009. ${ }^{4}$ Why did we use the sample data of BLCU's HSK rather than the New HSK? First, the BLCU's HSK has a longer history. The BLCU's HSK had advanced based on experience in CSL proficiency testing design and practice of over 26 years (1984-2010). During this time, researchers conducted many empirical investigations to improve the test (e.g., Chai, 2006; Cheng, 2006; Huang, 2006). Thus, these studies verified the BLCU's HSK reliability and validity (Meyer, 2014). Second, the BLCU's HSK mainly focuses on examinees' integrative ability of four language skills (listening, speaking, reading, and

\footnotetext{
${ }^{4}$ The sample selected from examinees taking different HSKs in different months of the year. Scores of each HSK were comparable after equivalent processing. In addition, previous research (see Meyer, 2014) showed no significant statistical difference in the difficulty of HSKs over the years. Items of one HSK are selected from different parallel versions in pretest trials according to difficulty and discrimination, which ensures the compatibility of HSKs.
} 
writing) and communicative competence, which is more applicable for this study.

The HSK consists of three levels of CSL proficiency: beginning level (HSK Basic), intermediate level (HSK ElementaryIntermediate), and advanced level (HSK Advanced). Learners who have mastery of 2,000-5,000 Chinese words and certain grammar rules are at the HSK Elementary-Intermediate level. This level covers learners with a wider range of proficiency than other HSK levels. HSK Elementary-Intermediate consists of four subtests (i.e., listening [50 items], grammar structure [30 items], reading [50 items], and cloze [ 40 items]), with 170 items in total. Of these, 1-154 items are multiple choice and 155-170 items are fill-in-the-blanks. This study focused on the results of two sections: the reading section and character writing part of the cloze section.

\section{Variables}

In total, this study inspected six variables: one dependent variable (CSL reading proficiency), two control variables (gender and age), and three independent variables (an individual-level variable, Chinese character writing proficiency [CCWP], and two group-level variables, language distance and cultural background).

\section{Chinese as a Second Language Reading Proficiency}

The data on CSL reading proficiency came from the results of the HSK reading test. The whole HSK reading section lasted $60 \mathrm{~min}$ and consisted of two parts: word substitution and paragraph reading. The first part examined the ability of students to understand, recognize, and use words in specific contexts. Within the first part, the test gave 20 sentences with words underlined. Then, examinees chose the best words with the most similar meaning and usage from four options to replace the underlined word in each sentence. The second part examined the competence of students in paragraph reading comprehension and reading speed within a given time. For example, competence consisted of summarizing and interpreting texts, extracting keywords and sentences, deducing implicit information, and identifying attitudes, moods, opinions, or intentions of authors. The test contained six to eight short articles of varying lengths, difficulties, forms, and topics. In addition, examinees answered 30 multiple-choice questions (one point per item), Figures 1, 2, respectively, show sample tests in the first and second parts of the HSK reading test.

\section{Chinese Character Writing Proficiency}

The study used the phrase "CCWP" to refer to Chinese character writing test scores that students got in the HSK test. The second part of the HSK cloze section was the basis of the CCWP data. This part mainly examined students' CSL orthographic competence of mastery and usage of lexical words and writing. Test-takers filled in 16 blanks (one point per blank) within the orthography part with appropriate and correct handwritten Chinese characters based on three to four passages that were give. The whole cloze section lasted for a total of $30 \mathrm{~min}$. Figure 3 shows a sample test in the HSK character writing test.
The CCWP was divided into two groups with low and high writing proficiency (baseline $=$ low level, score lower than an HSK character handwriting test score of 7/16). ${ }^{5}$

\section{Language Distance}

This study computed the language distance between participants' L1s and Chinese through the Automated Similarity Judgement Program (ASJP) database. ASJP is an extensive cross-linguistic linked database belonging to the Max Planck Institute. The latest version (19th edition) of ASJP (Wichmann et al., 2020) covers 40item word lists of 5,499 languages. These lists cover nearly $70 \%$ of the world's extant languages.

With consideration for language diversity, this study adopted the L1s of participants rather than the official languages of their nationalities. By applying the ASJP program (Bakker et al., 2009), we calculated language distance values using the Levenshtein Distance method comparing phonetic forms of 40 core words (Holman et al., 2008; see Table 1). The less linguistically similar an L1 is to Chinese, the higher the ASJP value. The language distance ranged from 0 to $102.88(M=97.92, S D=6.7)$.

\section{Cultural Background}

Based on previous studies (Pae, 2020; Tang and Chan, 2021), Sinosphere contains five entities: China, Japan, North Korea, South Korea, and Vietnam. Some researchers prefer to divide Sinosphere into two categories: the "Chinese cultural sphere" and the "non-cultural sphere." Others include South Asian countries (such as Laos and Singapore), with the limited L1 of learners influenced by the Chinese language and culture. For instance, they do not use Chinese characters in their language systems (B. Zhang, 2020). However, the dichotomy overlooks the individual differences caused by the influence of the L1 backgrounds of learners, CSL environments, and cultural factors (Li and Zhang, 2021). Thus, this study divided the sample by participants' language context of current residence into three groups: the narrow-Sinosphere (NSG, i.e., learners from Japan, North Korea, South Korea, and Vietnam), broad-Sinosphere (BSG, i.e., learners from 10 Southeast Asian countries: Laos, Cambodia, Thailand, Burma, Malaysia, Singapore, Indonesia, Brunei, the Philippines, and East Timor) and non-Sinosphere (non-SG, i.e., learners from all other countries) groups (baseline $=$ NSG).

\section{Control Variables}

Previous research has suggested that differences between males and females and children and adults may influence L2 reading and writing development (Phakiti, 2003; Jeon and Yamashita, 2014; Van der Slik et al., 2015; Vilas et al., 2019). However, reasons for the variation are still under investigation. This study controlled for the gender and age demographics of the examinees. Following previous research, two controlled variables

${ }^{5}$ On the one hand, this study dichotomized CCWP into two groups to explore the between-group variance and cross-group interaction effects. On the other hand, this study grouped CCWP to keep the practical importance of results. In our study, CCWP was measured with total scores [16 points] in the HSK character writing part (one character per point). The point gap is too small to explain the variation in reality. The dichotomization of CCWP did not change the main results of this study. 


\section{三、阅 读 理 解 \\ (共 50 题, 60 分钟) \\ 第一部分}

说明: 81-100 题, 每个句子中都有一个画线的词语, A B C D 四个答案是对这一画线的词 语的不同解释。请选择最接近该词语的一种解释 (在答卷上的字母上画一条横道)。

81. 他提出了一个很关键的问题。
A. 愚蚌
B. 复杂
C. 重要
D. 特殊

82. 从这里到大本营路途遥远、地形复杂, 我们最好早点儿动身。
A. 起床
B. 出发
C. 准备
D. 休息

83. 靠科学技术进步, 少花钱、省时间、 效益好。
A. 利用
B. 节约
C. 消耗
D. 安排

84. 静下心来琢穈的时候, 我就有种不祥 的预感。
A. 放松
B. 学习
C. 讨论
D. 思考

85. 她吃惊地望着他, 似乎不知道他刚才 在说些什么。
A. 确实
B. 好像
C. 一直
D. 仍然

86. 大家都从他的神色中隐隐约约感到了 一些异常。
A. 状态
B. 动作
C. 表情
D. 话语

87. 我必须到镇上走一趟, 采购一星期的 食物。
A. 要
B. 带
C. 找
D. 买

88. 她回答得很谨慎, 她说: “就算是吧, 那又怎么样? ”
A. 痛快
B. 得意
C. 小心
D. 自信

FIGURE 1 | Sample test in the first part of the Hanyu Shuiping Kaoshi (HSK) reading test.

were encoded as dichotomous, specifically, males as 1 , females as 0 , children (under 18 years old) as 0 , and adults as 1 .

\section{Data Analysis}

This study employed a two-level hierarchical linear model (HLM) to investigate the contributions and interaction effects of individual- and group-level variables on CSL reading (Hox, 2010). HLM is a statistical technique to analyze variance in the dependent variables by modeling the hierarchy of the nested structure of the data; for example, in this study, learners in a country shared variance of reading proficiency according to their common L1s. Considering within- and betweengroup regressions, this study used HLM software version 6 (Raudenbush et al., 2006) with a restricted maximum likelihood method to depict how the individual- and group-level predictors affected the reading proficiency of the students. Both the categorical variables (CCW and cultural background) were dummy-coded and added in the equation uncentered. All continuous variables involved in interaction effects were grand mean centered to avoid multicollinearity (e.g., Hofmann and Gavin, 1998; Enders and Tofighi, 2007).

Practically, the process of hierarchical model establishment could be divided into four steps (Heck et al., 2013): (1) null model, (2) individual-level (or level 1) random coefficient regression model, (3) group-level (or level 2) means-as-outcomes regression model, and (4) full model. Null model was regarded as the baseline model without any predictors for subsequent model comparison. The null model developed the levels 1 and 2 models 


\section{第二 部 分}

说明: 101-130 题, 每段文字后都有若干个问题, 每个问题都有 A B C D 四个答案。请快 速阅读并根据它的内容选择唯一恰当的答案(在答卷上的字母上画一条横道)。

$101-105$

我是一个近视眼, 所以有着近视眼们 的通病: 经常看不清东西。因为看不清, 所以就喜欢凑近些, 近些, 再近些。于是, 很多时候就一头撞上玻璃。 记忆里第一次撞玻璃是小时候和母亲 去糕点店买点心, 我十分专注地盯着玻璃 柜台里的绿豆糕发呆, 头慢慢低下去, 结 果 “梆” 的一声，我又大又亮的额头和亮 晶晶的柜台玻璃结结实实地亲了个嘴。我 差红了脸, 右手捂着发痛的额头, 左手牵 着母亲逃也似地离开了那个店。

人家都说, 岁月使人成长, 生活教人 改变。很可惜的是, 在撞玻璃这件事上, 我好像没有一点长进。十几年过去了, 没 有撞得最狠, 只有撞得更狠。

有一次, 在上电梯的时候, 我结结实 实撞上了电梯门, 撞得头破血流, 半夜送 急诊缝了六针才罢休。而给我挂号的一个 阿姨, 也笑着和我们分享了她的头撞车门 的惨痛经历。看来撞头这件事, 实在是人 生从小到大不得不经历的一个过程, 说起 来, 每个人大概都能表露一段心酸史呢。 这种物理性质的撞, 虽然在撞的过程 中疼痛剧烈, 可事后大多并不会留下多么 痛苦的回忆, 那些尴尤又好笑的瞬间反而 大多数在日后都会带给人们轻松和愉快。 而真正生活中的撞墙, 却往往是心灵中一 段封闭了的, 不愿触及和回想的痛苦。被 朋友出卖的心情便是如此。被亲人抛弃、 被同学拒绝, 都是如此。

人生里的这些墙, 如果都能够拿出撞 上玻璃门后又痛又笑的心情来对待, 大概 就没有解不开的死结, 过不去的困难了。 最痛苦的时刻, 往往是给人以最深刻启迪 和记忆的珍贵瞬间, 很多人生最宝贵的经 验, 甚至心灵的涅槃, 都发生在那电光火 石的一秒钟里。忍过去, 就是天堂, 放弃 了, 才是地狱。
【101】作者提到自己常撞头和什么有关?
A. 眼睛近视
B. 喜欢观察
C. 常常得眼病
D. 爱去糕点店

【102】根据文章, 作者为什么逃离糕点店?
A. 撞了门
B. 撞了人
C. 撞了柜台
D. 撞了桌子

【103】帮作者挂号的阿姨, 谈到自己撞头的 经历时, 心情怎么样?
A. 非常激动
B. 特别失望
C. 感到高兴
D. 觉得好笑

【104】作者认为生活中撞墙和不小心撞头有 什么不同?
A. 不小心撞头并不好笑
B. 生活中撞墙并不痛苦
C. 不小心撞头并不疼痛
D. 生活中撞墙很难恢复

【105】这篇文章主要反映作者怎样的人生态 度?
A. 乐观的
B. 消极的
C. 认真的
D. 游戏式的

FIGURE 2 | Sample test in the second part of the HSK reading test.

by adding variables at each hierarchical level. The final model included full variables of the two levels for investigating statistical relationships with reading proficiency.

The level 1 equation is as follows:

$Y_{i j}=\beta_{0 j}+\beta_{1 j}\left(G E N D E R_{i j}\right)+\beta_{2 j}\left(A G E_{i j}\right)+\beta_{3 j}\left(C C W P_{i j}\right)+r_{i j}$,

where $Y_{i j}$ is the reading test score for student $i$ within $L 1$ unit $j, \beta_{0 j}$ is the level 1 intercept (overall mean scores in the reading test for students with various genders and handwriting levels). $\beta_{1 j}, \beta_{2 j}$, and $\beta_{3 j}$ are, respectively, the regression coefficients (slopes) for the two dichotomous control variables GENDER and AGE, and $r_{i j}$ presents the residual error of the equation.

The level 2 equation of the random intercept model for estimating level 1 means is:

$$
\beta_{0 j}=\gamma_{00}+\gamma_{01}\left(A S J P_{j}\right)+\gamma_{02}\left(B S G_{j}\right)+\gamma_{03}\left(\text { non }-S G_{j}\right)+\mu_{0 j} \text {, }
$$

where $\gamma_{00}$ is the level 2 intercept (i.e., overall mean scores of reading test for an L1 unit $j$ ). $\gamma_{01}$ is the average slope coefficient and predicts the change in $\beta_{0 j}$ for one standard deviation change in language distances (ASJP). $\gamma_{02}$ and $\gamma_{03}$ are the expected changes of two predictors BSG and non-SG in $\beta_{0 j}$ (compared with 


\section{第二部 分}

说明: 155-170 题, 每段话中都有若干个空儿 (空儿中标有题目序号)。请根据上下文的意 思在答卷上的每一个空格中填写一个恰当的汉字。

$155-162$

亲爱的妈妈:

您好!

5 月 13 日, 就是母亲节了, 作为您的女儿, 我想真诚地说一声: “妈妈, 节日 155 乐!”

妈妈, 您不仅给了我生 $1 \mathbf{5 6}$, 在我人生的旅途中, 您更是用尽心血。正是有了您的早出晚

归, 才有了我丰衣足食的生活, 这个养育之恩我永 157 不会忘记。

妈妈, 您用您的爱 158 暖了我, 让我 159 福; 您的鼓励催我奋进; 您用贴心的话语安 160

我, 让我享 161 生活的阳光。

谢谢您, 我亲爱的妈妈!

祝妈妈身体 162 康!

$163-166$

会议通知

本俱乐部决定于 5 月 25 号 (星期日) 晚上 7 点 30 分, 在俱乐部召开会议。

会议内容包括: 向此次为灾区捐赠人员致谢; 汇报灾区前方的情 163 。届时, 请全体参与

此次捐款活动的人员参 164 , 俱乐部免 165 供应晚餐。会议重要, 请务必出 166 !

俱乐部地址: 都市路 3597 号

联系电话: 34510760

$167-170$

辞职信

肖总:

我自 2005 年来报社后一 167 在发行部工作, 三年来在各级领导的关心与 $\underline{168}$ 养下, 努力 工作, 圆满地完成了各项任务, 也取得了一定的成绩, 得到了领导的肯定, 本人表示十分感谢。 但由于自己感觉业务水平急需提高, 特此申请辞去我现在的职务, 以便参加业务进修。

感谢领导多年来对我的 169 持和勉励, 在此我衷心地道声谢谢! 望领导能够 170 准我的请 求。

发行部 李凡

2008 年 10 月 3 日

FIGURE 3 | Sample test in the HSK character writing test.

NSG). $\mu_{0 j}$ is the residual variance of $\mathrm{L} 1$ unit $j$ after controlling for GENDER. The level 2 model for estimating level 1 slopes with cross-level interaction for two levels is:

$$
\begin{aligned}
& \beta_{1 j}=\gamma_{10}+\mu_{1 j}, \\
& \beta_{2 j}=\gamma_{20}+\mu_{2 j},
\end{aligned}
$$

$\beta_{3 j}=\gamma_{30}+\gamma_{31}\left(A S J P_{j}\right)+\gamma_{32}\left(B S G_{j}\right)+\gamma_{33}\left(n o n-S G_{j}\right)+\mu_{3 j}$,

where $\gamma_{10}, \gamma_{20}$, and $\gamma_{30}$ are, respectively, the variances of the two control variables (GENDER and AGE) and level 1 predictor CCWP in the reading proficiency slope across L1s. The term " ${ }_{31}\left(\mathrm{ASJP}_{j}\right)+{ }_{\gamma 32}\left(\mathrm{BSG}_{j}\right)+{ }_{\gamma 33}\left(\right.$ non-SG $\left.G_{j}\right)$ " states that the relationship between reading proficiency $(\mathrm{Y})$ and handwriting level (X) of an individual depends on language distance (ASJP) and cultural background (BSG and non-SG). $\mu_{1 j}, \mu_{2 j}$, and $\mu_{3 j}$ represent the residual variance of the L1 unit $j$ on the predicted GENDER slope $\left(\beta_{1 j}\right)$, AGE slope $\left(\beta_{2 j}\right)$, and CCWP slope $\left(\beta_{3 j}\right)$.

\section{RESULTS}

\section{Descriptive Statistics}

For the combined sample of 74,362 CSL learners, the overall mean scale scores were $27.76(S D=10.17)$ and $6.52(S D=4.27)$ for the HSK reading and handwriting tests, respectively. For 
TABLE 1 | Descriptive statistics of participants with language distance between L1s and Chinese.

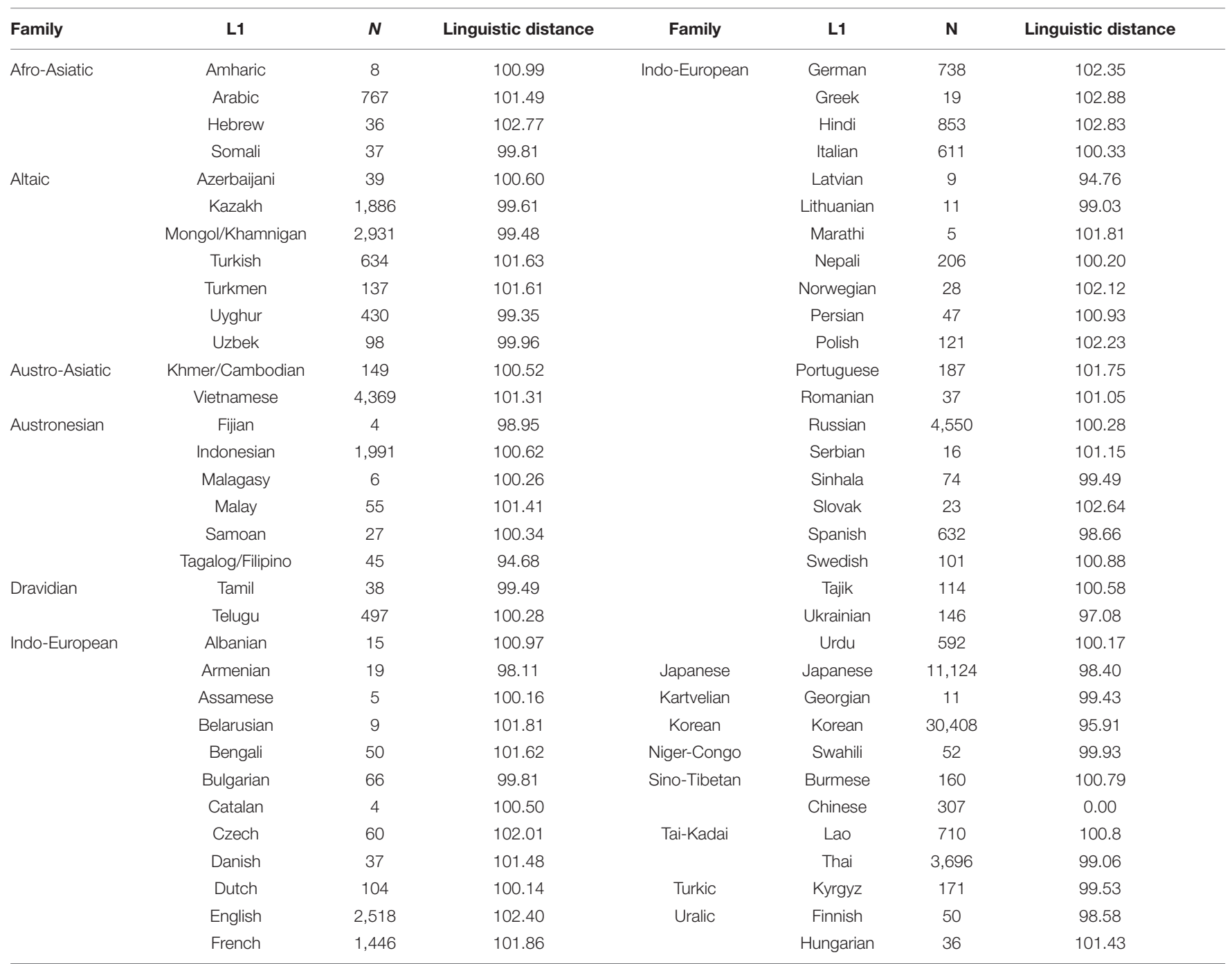

Sort in alphabetical order.

children (age $<18$ ), mean scores in the reading and writing tests were $25.55(S D=9.81)$ and $6.30(S D=4.06)$, respectively. For adult learners, the mean scores in the two tests were 28.11 $(S D=10.18)$ and $6.55(S D=4.30)$, respectively. At the group level, for the sample of $67 \mathrm{~L} 1 \mathrm{~s}$, the mean language distance was 98.79 $(S D=12.38)$.

Before HLM analysis, this study tested the multicollinearity of all the variables. Results of variance inflation factors (VIFs) (all VIFs $<3$ ) show that there was no multicollinearity in the model (Tabachnick and Fidell, 2013). Table 2 summarizes the description of these variables.

\section{Model Specifications}

This study started with a basic model, the null model. The null model involved only intercept items to account for how much of the variance in reading scores lay between the L1 units in the sample. According to the results of the unconditional model, the average reading test score across L1 units was 24.97, $p<0.001$. The between-language variation, $\tau_{00}=21.56$, $\chi^{2}(66)=19,519.34, p<0.001$, indicated significant differences among learners' L1s in their mean scores in reading proficiency. The within-language variation was $\sigma^{2}=88.10$. The intraclass correlation coefficient (ICC1) estimates the proportion of grouplevel variance in the population. Thus, when ICC1 $\geq 0.10$, it is valid to use HLM (Raudenbush and Bryk, 2002). In this study, ICC $1=\frac{\sigma_{\mu_{0}}^{2}}{\sigma_{\mu_{0}}^{2}+\sigma_{e}^{2}}=21.56 /(21.56+88.10)=0.20$. Therefore, the results indicated that of the $0.36\left(\tau_{00}+\sigma^{2}=0.36\right)$ variance in reading scores, the variance caused by group differences was 21.56, accounting for $20 \%$ of the overall variance. In comparison, the other $80 \%$ of the variance came from individual differences. The estimated inter-rater reliability (ICC2) was 0.90 . Such substantial reliability meant a reliable estimation of these models. Thus, adopting multilevel analysis was valid.

Next, level 1 predictors (gender, age, and CCWP) were added into the baseline model as a random coefficient regression model. No group-level predictors were entered this model. Except for age 
TABLE 2 | Descriptive statistics for the dependent variable (Chinese as a second language, CSL, reading proficiency) and explanatory variables (67 L1s from 173 countries).

\begin{tabular}{|c|c|c|c|c|c|c|}
\hline & & & \multicolumn{2}{|c|}{ Children $(N=8,053)$} & \multicolumn{2}{|c|}{ Adult $(N=38,464)$} \\
\hline & & & Mean & $S D$ & Mean & $S D$ \\
\hline \multirow[t]{7}{*}{ NSG $(N=46,517)$} & CSL reac & & 26.35 & 9.42 & 30.61 & 9.44 \\
\hline & CCWP & & 6.67 & 3.91 & 7.73 & 3.95 \\
\hline & Age & & 16.01 & 1.69 & 25.39 & 7.39 \\
\hline & Languag & & 95.76 & 5.71 & 97.05 & 5.02 \\
\hline & & & $N$ & $\%$ & $N$ & $\%$ \\
\hline & Gender & Male & 4,756 & $59 \%$ & 18,539 & $48 \%$ \\
\hline & & Female & 3,297 & $41 \%$ & 19,925 & $52 \%$ \\
\hline \multirow[t]{8}{*}{$\mathrm{BSG}(N=6,897)$} & & & Mean & $S D$ & Mean & $S D$ \\
\hline & CSL reac & & 25.45 & 10.61 & 26.31 & 9.22 \\
\hline & CCWP & & 6.44 & 4.35 & 6.47 & 4.11 \\
\hline & Age & & 16.57 & 1.48 & 22.90 & 4.20 \\
\hline & Languag & & 98.70 & 11.20 & 98.82 & 9.79 \\
\hline & & & $N$ & $\%$ & $N$ & $\%$ \\
\hline & Gender & Male & 257 & $46 \%$ & 2,198 & $35 \%$ \\
\hline & & Female & 301 & $54 \%$ & 4,141 & $65 \%$ \\
\hline \multirow[t]{8}{*}{ Non-SG $(N=20,948)$} & & & Mean & $S D$ & Mean & $S D$ \\
\hline & CSL reac & & 21.49 & 10.42 & 23.74 & 10.29 \\
\hline & CCWP & & 4.34 & 4.14 & 4.23 & 4.05 \\
\hline & Age & & 16.68 & 1.45 & 22.91 & 4.40 \\
\hline & Languag & & 98.78 & 10.93 & 100.19 & 7.43 \\
\hline & & & $N$ & $\%$ & $N$ & $\%$ \\
\hline & Gender & Male & 860 & $54 \%$ & 9,918 & $51 \%$ \\
\hline & & Female & 727 & $46 \%$ & 9,443 & $49 \%$ \\
\hline
\end{tabular}

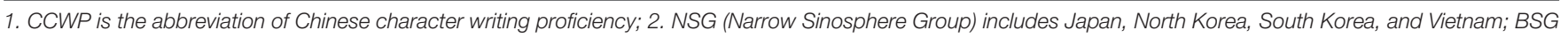

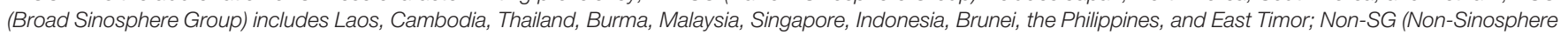
Group) includes countries outside East Asia.

(0.46, $S E=0.44, p>0.05)$, the effects of both gender $(-0.56$, $S E=0.18, p<0.01)$ and CCWP (12.50, $S E=0.36, p<0.001)$ were highly significant, i.e., female learners may get better reading proficiencies than male learners. Thus, the higher the CCWP of learners, the better their reading proficiency. Children did not differ in reading proficiency from adult learners.

Then, we estimated the means-as-outcomes regression model with only group-level predictors. This model regressed average reading proficiency on language distance and variant cultural backgrounds. The effect of language distance $(-0.062$, $S E=0.01, p<0.001)$ was significant, indicating that the more linguistically similar learners' L1s and Chinese, the better their proficiency in CSL reading. Compared with NSG learners, learners from Southeast Asian countries $(-5.30, S E=2.98$, $p>0.05$ ) had no significant variance in reading from NSG learners. However, learners from non-Sinosphere countries $(-9.64, S E=2.18, p<0.001)$ scored lower in reading than the NSG learners.

Finally, we estimated the full model with individual-level and group-level variables (see Table 3 for results of the final model). The level 1 model included the intercept and three slopes: gender, age, and CCWP. These three variables also served as a predictor of level 1 means and language distance, NSG, BSG, and non-SG s slopes in the level 2 model.

\section{Final Explanatory Models \\ Estimating the Means}

The main purpose of the final model analysis was to explore the main and interaction effects of CCWP, language distance, and cultural background on the reading proficiency of the learners after controlling for gender and age. In Table 3, the L1 mean base value $\left(\gamma_{00}=24.68, S E=0.62, p<0.001\right)$ indicates the average reading score for the reference student. This reference student was an adult female with a narrow Sinosphere cultural background and an average language distance between L1 and Chinese and mastered high Chinese character writing skills. The mean reading score of this student was 24.68 .

$\mathrm{H}_{1}$ addressed the relationship between CCWP and reading proficiency. The regression coefficient for CCWP was 12.48 $\left(\gamma_{30}=12.48, S E=0.34, p<0.001\right)$. Since CCWP was coded as $0=$ low and $1=$ high, this meant that, on average, learners with high CCWP scored 12.48 points higher on the reading test. Accordingly, this finding supported $\mathrm{H}_{1}$.

The language distance was negatively correlated to the average reading score $\left(\gamma_{01}=-0.06, S E=0.01, p<0.001\right)$. This result meant that the average reading scores should decrease by 0.06 scale points, each standard deviation higher on the language distance. This prediction does not seem very much, but the language distance in this study ranges from 0 to 102.88 , so 
TABLE 3 | Final hierarchical linear models (HLMs) predicting reading proficiency.

\begin{tabular}{|c|c|c|c|c|c|c|c|c|}
\hline \multirow[t]{2}{*}{ Fixed effects } & \multicolumn{2}{|c|}{ Null Model } & \multicolumn{2}{|c|}{ Level 1 Model } & \multicolumn{2}{|c|}{ Level 2 Model } & \multicolumn{2}{|c|}{ Full Model } \\
\hline & Coefficient (S.E.) & T-ratio & Coefficient (S.E.) & T-ratio & Coefficient (S.E.) & T-ratio & Coefficient (S.E.) & T-ratio \\
\hline \multicolumn{9}{|l|}{ L1s mean $\left(\beta_{0 j}\right)$} \\
\hline Base $\left(\gamma_{00}\right)$ & $24.97(0.59)$ & $42.06^{\star \star \star}$ & $21.26(0.53)$ & $40.36^{\star \star \star}$ & $39.35(1.43)$ & $27.58^{\star \star \star}$ & $24.68(0.62)$ & $39.60^{\star \star \star}$ \\
\hline $\operatorname{ASJP}\left(\gamma_{01}\right)$ & & & & & $-0.06(0.01)$ & $-5.66^{\star \star \star}$ & $-0.06(0.01)$ & $-6.39^{\star \star \star}$ \\
\hline Broad Sinosphere $\left(\gamma_{02}\right)$ & & & & & $-5.31(2.98)$ & -1.78 & $-6.62(2.64)$ & $-2.50^{\star \star}$ \\
\hline Non-Sinosphere $\left(\gamma_{03}\right)$ & & & & & $-9.64(2.18)$ & $-4.42^{\star \star \star}$ & $-10.71(1.92)$ & $-5.56^{\star \star \star}$ \\
\hline \multicolumn{9}{|l|}{ Gender $\left(\beta_{1 j}\right)($ Male $=1)$} \\
\hline Base $\left(\gamma_{10}\right)$ & & & $-0.56(0.18)$ & $-3.11^{\star \star}$ & & & $-0.48(0.18)$ & $-2.75^{\star \star}$ \\
\hline \multicolumn{9}{|l|}{ Age $\left(\beta_{2 j}\right)($ Adult $=1)$} \\
\hline Base $\left(\gamma_{20}\right)$ & & & $0.46(0.44)$ & 1.03 & & & $0.47(0.45)$ & 1.04 \\
\hline \multicolumn{9}{|l|}{$\operatorname{CCWP}\left(\beta_{3 j}\right)($ high level = 1) } \\
\hline Base $\left(\gamma_{30}\right)$ & & & $12.50(0.36)$ & $35.17^{\star \star \star}$ & & & $12.48(0.34)$ & $36.73^{\star \star \star}$ \\
\hline $\operatorname{ASJP}\left(\gamma_{31}\right)$ & & & & & & & $-0.06(0.00)$ & $-12.03^{\star \star \star}$ \\
\hline Broad Sinosphere $\left(\gamma_{32}\right)$ & & & & & & & $-0.12(0.81)$ & -0.15 \\
\hline Non-Sinosphere $\left(\gamma_{33}\right)$ & & & & & & & $0.72(0.65)$ & 1.12 \\
\hline Random effects & Variance $(S D)$ & Chi-square & Variance $(S D)$ & Chi-square & Variance (SD) & Chi-square & Variance (SD) & Chi-square \\
\hline Between-L1s means $\left(\tau_{00}\right)$ & $21.56(4.64)$ & $19,515.67^{\star \star \star}$ & $9.32(3.05)$ & $468.27^{\star \star \star}$ & $12.01(3.47)$ & $12,496.10^{\star \star \star}$ & $16.62(4.08)$ & $5491.26^{\star \star \star}$ \\
\hline Gender slope $\left(\tau_{10}\right)$ & & & $0.81(0.90)$ & $177.50^{\star \star \star}$ & & & $0.75(0.87)$ & $182.79^{\star \star \star}$ \\
\hline Age slope $\left(\tau_{20}\right)$ & & & $4.43(2.15)$ & $1,025.48^{\star \star \star}$ & & & $3.60(1.90)$ & $677.82^{\star \star \star}$ \\
\hline $\operatorname{CCWP}\left(\tau_{30}\right)$ & & & $4.63(2.10)$ & $536.02^{\text {***}}$ & & & $4.40(2.10)$ & $529.31^{\star \star \star}$ \\
\hline Within-L1s $\left(\sigma^{2}\right)$ & 88.10 & 9.39 & $58.65(7.66)$ & & & & $58.65(7.66)$ & \\
\hline Deviance & $544,198.22$ & & $514,166.28$ & & $544,252.92$ & & $514,178.90$ & \\
\hline
\end{tabular}

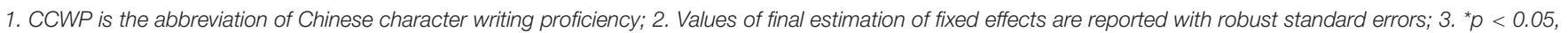
${ }^{* *} p<0.01$, and ${ }^{* * *} p<0.001 ; 4$. NSG is the reference category in the analysis.

the predicted difference between the closest and most distant languages is $(102.88-0) \times 0.06=6.17$ points on the reading test. This study also observed that, on average, the NSG learners outperformed their BSG and non-SG counterparts by 6.62 and 10.71 points, respectively. For the controlled variables, the results indicated a negative relationship between gender and reading score $\gamma_{10}(=-0.48, S E=0.18, p<0.01)$, but there was no significant difference between children and adult learners $\left(\gamma_{20}=0.47, S E=0.45, p>0.05\right)$.

\section{Estimating the Slopes}

In this model, we also added interaction effects to test if the influence of CCWP still held. Table 3 also displays the unique effects associated with the interactions of CCWP on reading proficiency.

$\mathrm{H}_{2}$ addressed the moderating effects of cultural background. Unexpectedly, this study found no interactions for cultural background. This result indicated that considering the main effects together, the beneficial effects of cultural background factors and CCWP were neither in conflict nor synergistic to learners' improvement in reading proficiency (the Discussion section addresses this further). Therefore, the findings did not support $\mathrm{H}_{2}$.

$\mathrm{H}_{3}$ addressed the moderating effects of language distance. The results revealed that there was a negative interaction between language distance and $\operatorname{CCWP}\left(\gamma_{31}=-0.06, p<0.001\right)$. Figure 4 provides a visual representation of this interaction, signifying that the effect of CCWP on reading proficiency can range from curbing to favorable, depending on the language distance between L1s and Chinese. Specifically, each standard deviation increase in language distance predicted a slight score decrease by 0.06 points, which was small but significant, in reading text for learners with high handwriting skills. These results suggested

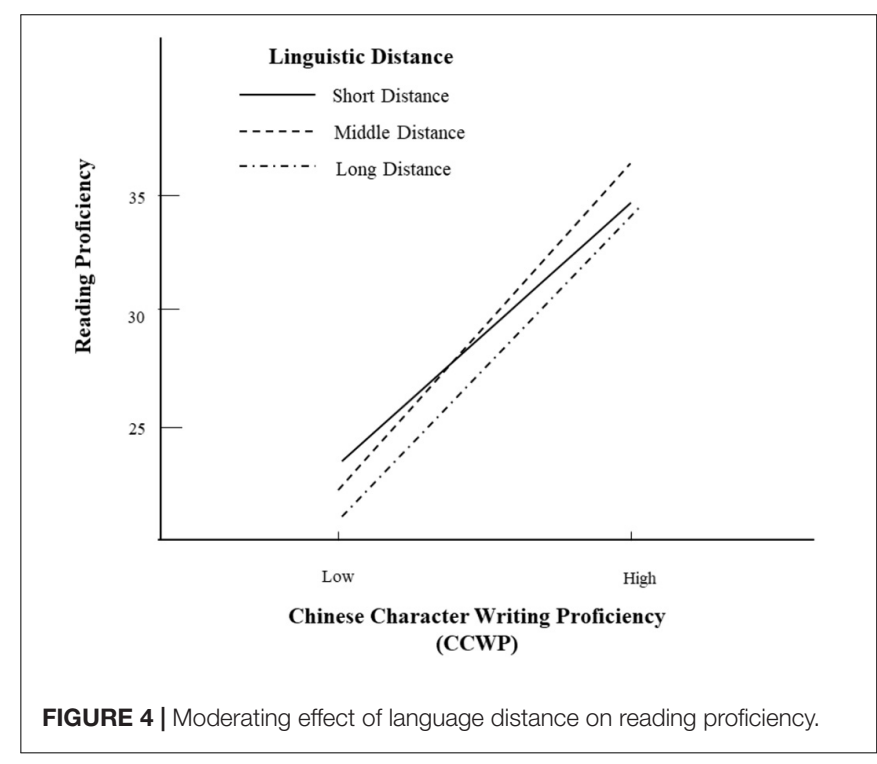


that learners proficient in handwriting still held their advantage in reading when their L1s were more distant from Chinese. Thus, this finding supported $\mathrm{H}_{3}$.

Moreover, outcomes of random effects showed the most variance between learners $\left(\sigma^{2}\right)$. This result indicated that individual differences of learners determined reading difficulty more than features of their L1s. This finding was not surprising, since learners succeed in reading development more through embodied activities, especially handwriting, than linguistic features. Interestingly, there was also variance between children and adults, although it was not significant. This finding may be due to the fairness of HSK design. Future research could explore more age-related factors to parse out this variance.

Finally, the model reported an $\sigma^{2}$ of 88.10 in the full model and 58.65 in the baseline model. According to these results, the effect size of explained variance (Cohen's $d=0.33$ ) for the full model was moderate (cutoff range: $0.15<d \leq 0.35$ ) (Cohen, 1988). This finding meant that the slope variance reduced sharply after introducing the predictors of two levels and interactions in the null model.

\section{DISCUSSION}

Although the role of the embodiment of Chinese characters in Chinese reading has been widely noted, only few studies involve HSK data on variant language backgrounds. This study was designed to investigate how three factors of Chinese character embodiment, CCWP, language distance, and cultural background, affected Chinese reading proficiency among 74,362 learners from 67 different L1s. First, this study found significant contributions of CCWP, language distance, and cultural background in reading proficiency. Second, there was a significant moderating effect of language distance. After controlling for gender and age, learners who were proficient in handwriting still held their advantage when their L1s were more distant from Chinese. Third, it was unexpected that cultural background had beneficial effects rather than no moderating effects on reading proficiency. These results broadly accord with the ECT.

\section{Relationships Between Chinese Handwriting and Reading Comprehension}

RQ1 set out to explore the positive influence of character writing on reading comprehension. First, as expected, CCWP showed a beneficial effect on the reading proficiency of learners. This finding further support the idea of the ECT and indicate that bodily graphomotor may facilitate the advanced cognition processing in reading (e.g., understanding, memorization, interpretation, and reasoning). This finding also concurs with the view of sociocultural theory (Vygotsky, 1978), which states that internal activity originates from external mediation (Swain, 2000; Ellis, 2008).

Notably, this finding does not mean it rejects the case study of $\mathrm{Bi}$ et al. (2009). On the contrary, this study attempted to provide a possible explanation for the debate. A possible explanation for these different results in the debate may be lack of adequate attention to the embodiment of Chinese characters. Thus, the experience of bodily activity and perception could couple with context as metaphors stored in one's mind (Leung et al., 2011). Due to this, the brain-injured patient could holistically extract the phonetic, morphological, and ideographic information of Chinese character forms after his brain injury. Thus, we rigorously claim that at least for elementary and intermediate CSL learners, character writing may be essential in reading development (Tan et al., 2005b; Lam and McBride, 2018).

Second, this study was unable to demonstrate the interaction effect of age. In line with previous research supporting the writing-to-reading issue, the results of this study suggest a close association between Chinese handwriting and reading in adults and children (e.g., Tan et al., 2005b; Guan et al., 2021; Yin and Zhang, 2021). This result may be explained by the fact that early writing experience could aid the holistic processing of character visual recognition for children (James, 2017) and adults (Tso et al., 2011).

\section{Role of Language Distance in the Relationships Between Chinese Handwriting and Reading Comprehension}

The RQ2 in this study attempted to answer the question of how past language experience (L1 background) moderated the relationship between character writing and reading. Crosslinguistic influence is always an inevitable topic in SLA. As expected, language distance negatively moderated the positive effect between CCWP and reading proficiency, which corroborated L1-L2 transfer theories that similar linguistic features between L1 and L2 promoted SLA achievement (Sharwood Smith and Kellerman, 1986; Odlin, 1989). In addition, these findings also showed that for learners with high CCWP, the advantage in CSL reading could still be held regardless of language distance. This finding was consistent with the empirical evidence in the brain and neuroscientific research that handwriting experience may shape the specialized neural representation and accelerate the visual processing of character formation in reading (Tan et al., 2005b; James and Atwood, 2009; Hu et al., 2018).

Another possible explanation for this is the view of mental simulation in the ECT. According to the ECT, the nature of mental activity (including metaphor interpretation, empathy, embodied learning, and language comprehension) is to resituate by mentally simulating a virtual world with which an individual is familiar (Zwaan and Taylor, 2006; Gibjr, 2010; Gallese, 2014). Piaget (1976) put forward that L1 learning was a sensorimotor process. Given this, L2 reading acquisition may be a mental simulation that could re-situate L2 symbols in the original sensorimotor memory trace of L1 learning. As such, researchers could build correlations between memory trace and L2 through vocabulary (Henning, 1973; Lindsay and Gaskell, 2010; Macedonia, 2014), sentences (Borreggine and Kaschak, 2006; Diefenbach et al., 2013; 
Papesh, 2015), and even passages (Zwaan, 2004, 2016), evidenced to promote language comprehension. Therefore, as an embodied activity, Chinese character writing may bridge the L1 sensorimotor memory and L2 scripts of learners by strengthening the link between body and situation. It seems that learners good at character writing can maintain these advantages in reading. As noted in the introduction, the sociocultural theory claims that internal mediation originates from external mediation, and we may infer that for intermediate learners, internal language experience is the medium between bodily activity and external language usage in CSL learning.

\section{Role of Cultural Background in the Relationships Between Chinese Handwriting and Reading Comprehension}

RQ3 investigated the role of cultural background in moderating the relationship between CSL character writing and reading. First, the results showed a significant effect of NSG and BSG on reading proficiency. This finding accorded with the research that intermediate learners from NSG and BSG are more proficient in reading than those from non-SG (Hsiao et al., 2015; Ke and Chan, 2017). In addition, the results further showed that CCWP could effectively distinguish between the NSG and BSG learners; that is, the NSG learners might be more proficient in reading than the BSG group. These initial results were suggestive of a relationship between cognition and context; that is, context embeds cognition and, in turn, contextual factors compose the cognition (Lakoff and Johnson, 1999; Rohrer, 2007). Even though the languages and cultures of most countries with Sinosphere cultural background have shifted, the cognitive and thinking patterns have not fallen far from the original Chinese. These results reflected those of studies (Yeh et al., 2003; Ke and Chan, 2017) that also found that readers with Chinese cultural backgrounds tend to use similar strategies in recognizing and reading characters.

Second, unlike our initial hypothesis, this study showed that CCWP $\times$ cultural background interaction effects were not statistically significant. Upon finding this result, we reconsidered whether there were any other important moderating factors at the individual level. However, there was no such factor in this study. This finding may indicate that for CSL beginners and intermediates, cultural background could not moderate the relationship between bodily activity and reading proficiency. In other words, for learners skilled in character writing, reading proficiency might fail to be constrained by non-Chinese cultural and contextual backgrounds.

One possible explanation for this finding of insignificant CCWP $\times$ cultural background interaction is differences in contexts. For the non-SG learners, because their L1s and Chinese belong to different systems, it may be difficult for them to correspond their L1s well with Chinese. Indeed, reading comprehension is a process in which the structural knowledge in the mind of a reader could interact with the text, meaning, and background of reading materials (Carrell and Eisterhold, 1983;
Carrell, 1984). Also, in fact, Chinese is not a global language like English. It is possible, therefore, that CSL learners cannot wherever and whenever connect with the Chinese language in daily life. In this study, the learners of CSL at the beginning and intermediate levels might have suffered from corresponding their individual experience and knowledge to reading texts well, especially when they read texts full of unfamiliar Chinese idioms, cultures, and customs. This finding provides some explanation as to why both handwriting and cultural background are irreplaceable aspects in reading acquisition investigation.

For NSG and BSG learners, although Sinosphere countries share culture and languages, dramatic changes in languages and cultures have occurred in both China and Sinosphere countries. On the one hand, some NSG countries, such as Korea and Vietnam, have canceled character teaching and usage because of educational policy reform. On the other hand, there are some overlaps between Sinosphere languages and Chinese, but discrepancies in cultural schema, meaning, and forms of characters still exist. These discrepancies may lead to errors in CSL reading (Ellis, 2008). For example, take a shared character “娘” in Japanese and Chinese as an example. In Japanese, “娘”, pronounced “musume," mainly means young girl and daughter. In Chinese, when one uses “娘” [niang2] alone, it fundamentally means mother rather than young girl, and the meaning "daughter" disappears. In addition, characters sharing the same meaning might differ in forms, such as “单," “饮”, and “个” in Chinese, or “単," “飲,” and “個” in Japanese. An implication of this is the possibility that learners from Sinosphere countries or skilled at character writing may still meet challenges during CSL reading (Ke, 1998; Jiang, 2003; Lin and Collins, 2012; Li, 2020; Tang and Chan, 2021; Zhang and Roberts, 2021b).

Going back to the question of Alderson of whether differences in reading proficiency are a reading problem or a language problem, based on the findings in this study, we cannot simply classify reading variance into dichotomous problems, at least for CSL learners. One of the issues that emerge from previous findings is that reading may be a more complicated cognitive process than what existing research knows. Therefore, we may prefer to regard the variance of reading as a mixed cognitive problem of reading, language, and conception, different problems that possibly appear in different learning periods.

\section{CONCLUSION}

Focusing on the role of CCWP in reading comprehension among CSL intermediates and adopting big data from HSK, this study contributed to a better understanding of the ECT in SLA. It revealed the embodied features of Chinese characters. First, CCWP had a positive effect on reading proficiency, which indicated an essential role of Chinese character handwriting in CSL reading. Second, language distance played a moderate role in the relationship between character writing and reading. The findings provided empirical evidence that character writing could constrain L1 negative transfer 
in CSL reading acquisition. Third, the cultural background of CSL learners could positively influence but might not moderate the relationship between character writing and reading proficiency.

\section{IMPLICATIONS}

\section{Theoretical Implications}

First, our study has highlighted the importance of handwriting in L2 reading. The results of this study illustrate that writing Chinese scripts by hand facilitates reading comprehension (Wang et al., 2014, 2015; Kuo et al., 2015; Tong and Yip, 2015; Tong et al., 2016; Chung et al., 2018; Zhang J. et al., 2020). In addition, the advantage of skilled character writing would remain even if L1 and L2 are linguistically distant (Sharwood Smith and Kellerman, 1986; Odlin, 1989).

Second, the findings in this study have provided a deeper insight into the cross-linguistic influence in SLA. For one thing, cross-linguistic influence occurs at the linguistic and conceptual levels (Jarvis and Pavlenko, 2008). In addition, for SLA beginners and intermediates, L1 experience may be the medium between bodily activity (i.e., character writing) and L2 usage. In turn, the L1-L2 cross-language congruity can moderate the correlations between bodily activity and L2 usage (Melby-Lervåg and Lervåg, 2011; Jeon and Yamashita, 2014). For another, language distance can be a measurement of cross-linguistic similarity or difference and may reflect the variance in L1-L2 embodied experience.

Third, this study has contributed new empirical evidence to the ECT that the effects of cultural background on investigations of CSL reading need to be reckoned with (Vygotsky, 1978; Ellis, 2008; Green and Abutalebi, 2013; Tong et al., 2016). For SLA learners in the primary stage, their L2 and the conceptual system are not completely established, and they are likely to rely on their L1 knowledge. Overall, there seems to be some evidence to indicate that although the influence of L1 cultural background on L2 scriptwriting is much less, the effect of L1 cultural background on $\mathrm{L} 2$ reading proficiency is more apparent.

\section{Practical Implications}

This study also has some practical implications. First, the findings of this study suggest that it is necessary to learn the knowledge of character writing orthography at the intermediate level of CSL acquisition (Lam and McBride, 2018; Zhou et al., 2020). This finding also indicates that CSL reading acquisition develops from embodied cognition.

The findings also provide suggestions for CSL acquisition that character writing by hand may benefit from withstanding the negative transfer from L1s. Thus, it is effective for CSL learners to learn character writing in CSL reading acquisition. Additionally, for CSL character teaching, teaching materials and methods are suggested to be more diversified for learners with different L1s and cultural backgrounds.

Moreover, in CSL teaching, teachers need to pay more attention to the sociocultural backgrounds of learners. For example, having a similar background with Chinese does not mean being more proficient in character writing and orthography. Thus, it is necessary for teachers to teach script motivation (i.e., correlations between character structures, radicals, and meanings, which translated from Chinese term “文字理据”) (Xu, 1992) of characters and keep students practicing correctly.

Finally, to help build the conceptual system of students, teachers could introduce similarities and differences in cultures, thoughts, and society between the countries of students and China, encouraging them to share their views and underlying cultural contexts (Carrell and Eisterhold, 1983).

\section{LIMITATIONS AND FUTURE RESEARCH}

One limitation in the current study is that group-level predictor cultural background data are crudely based on the countries of residence of the participants and separated into NSG, BSG, and non-SG. As a result, case studies are needed in the future to further investigate more elaborate differences among learners with variant sociocultural backgrounds.

In addition, this study explored the role of character writing of CSL beginners and intermediates. However, this focus was limited to studying other factors that predicted reading comprehension in previous studies, including linguistic knowledge, L1 and L2 literacy experience, age of acquisition, L2 proficiency, script distance, and measurement characteristics (Koda, 2007; Jeon and Yamashita, 2014). Therefore, future research could consider these predictors and further investigate correlations among them. Also, it would be beneficial to study other latent variables (e.g., belief and anxiety) to investigate the non-linear relationship between CSL writing and reading, and how they vary across different groups ${ }^{6}$.

Finally, this study only explored the relationships between Chinese character handwriting and Chinese reading using the ECT at a macroscopic level. Future research could further examine the mechanism of embodiment in cognitive processing in the brain and neuroscientific technology at a microscopic level.

\section{DATA AVAILABILITY STATEMENT}

The raw data supporting the conclusions of this article will be made available by the authors, without undue reservation.

\section{ETHICS STATEMENT}

The studies involving human participants were reviewed and approved by Institute on Educational Policy and Evaluation of International Students, Beijing Language and Culture University. Written informed consent from the participants' legal guardian/next of kin was not required to participate in this study in accordance with the national legislation and the institutional requirements.

\footnotetext{
${ }^{6}$ We wish to acknowledge the reviewer who offered this advice.
} 


\section{AUTHOR CONTRIBUTIONS}

XC and MM conceived and designed the work. MM performed the statistical analysis and wrote the first draft of the manuscript. $\mathrm{XC}$ revised the manuscript critically. Both authors contributed to manuscript revision, read, and approved the submitted version.

\section{FUNDING}

This project was supported by the Key Projects of the National Social Science Fund of China (Award Number 17AYY011). The

\section{REFERENCES}

Addy, L. M. (1996). A perceptuo-motor approach to handwriting. Br. J. Occup. Ther. 59, 427-432. doi: 10.1177/030802269605900909

Alderson, J. C. (1984). "Reading in a foreign language: a reading problem or a language problem?", in Reading in A Foreign Language, eds J. C. Alderson and A. H. Urquhart (London: Longman), 1-24.

Allen, J. R. (2008). Why learning to write Chinese is a waste of time: a modest proposal. Foreign Lang. Ann. 41, 237-251. doi: 10.1111/j.1944-9720.2008. tb03291.x

Anderson, J. A. E., Hawrylewicz, K., and Bialystok, E. (2020). Who is bilingual? Snapshots across the lifespan. Biling 23, 929-937. doi: 10.1017/ s1366728918000950

Bakker, D., Müller, A., Velupillai, V., Wichmann, S., Brown, C. H., Brown, P., et al. (2009). Adding typology to lexicostatistics: a combined approach to language classification. Linguist. Typol. 13, 169-181. doi: 10.1515/lity.2009.009

Barsalou, L. W. (2008). Grounded cognition. Annu. Rev. Psychol. 59, 617-645. doi: 10.1146/annurev.psych.59.103006.093639

Berkes, M., Friesen, D. C., and Bialystok, E. (2018). Cultural context as a biasing factor for language activation in bilinguals. Lang. Cogn. Neurosci. 33, 10321048. doi: 10.1080/23273798.2018.1446541

Bi, Y., Han, Z., and Zhang, Y. (2009). Reading does not depend on writing, even in Chinese. Neuropsychologia 47, 1193-1199. doi: 10.1016/j.neuropsychologia. 2008.11.006

Borreggine, K. L., and Kaschak, M. P. (2006). The action-sentence compatibility effect: it's all in the timing. Cogn. Sci. 30, 1097-1112. doi: 10.1207/ s15516709cog0000_91

Brown, A., and Gullberg, M. (2008). Bidirectional crosslinguistic influence in L1L2 encoding of manner in speech and gesture: a study of Japanese speakers of English. Stud. Sec. Lang. Acquis. 30, 225-251. doi: 10.1017/S0272263108080327

Brown, A., and Gullberg, M. (2011). Bidirectional cross-linguistic influence in event conceptualization? Expressions of path among Japanese learners of English. Bilingualism 14, 79-94. doi: 10.1017/S1366728910000064

Brunelle, M., and Kirby, J. (2016). Tone and phonation in southeast Asian languages: tone and phonation in southeast Asian languages. Lang. Linguist. Compass 10, 191-207. doi: 10.1111/lnc3.12182

Bylund, E., Athanasopoulos, P., and Oostendorp, M. (2013). Motion event cognition and grammatical aspect: evidence from Afrikaans. Linguistics 51, 929-955. doi: 10.1515/ling-2013-0033.

Carrell, P. L. (1984). Schema theory and ESL reading: classroom implications and applications. Mod. Lang. J. 68, 332-343. doi: 10.1111/j.1540-4781.1984.tb02 509.x

Carrell, P. L., and Eisterhold, J. C. (1983). Schema theory and ESL reading pedagogy. TESOL Q. 17, 553-573. doi: 10.2307/3586613

Chai, X. (2006). “关于HSK(初、中等)平行信度的实证研究 [Empirical research on the parallel test reliability of the Elementary-Intermediate HSK], in 汉语水平考试研究 [HSK Research], ed. K. Zhang (Beijing: The Commercial Press), 184-194.

Chang, L. Y., Chen, Y. C., and Perfetti, C. A. (2018). GraphCom: a multidimensional measure of graphic complexity applied to 131 written languages. Behav. Res. Methods 50, 427-449. doi: 10.3758/s13428-017-0881-y

Chang, L. Y., Stafura, J. Z., Rickles, B., Chen, H. C., and Perfetti, C. A. (2015). Incremental learning of Chinese orthography: ERP indicators of research is also supported by the Key Projects of Beijing Language and Culture University Fund (Award Number 19ZDJ04).

\section{ACKNOWLEDGMENTS}

The content is solely the responsibility of the authors and does not necessarily represent the official views of the National Social Science Fund of China and Beijing Language and Culture University. We would like to thank the examinees and test centers who helped us gather the data.

animated and static stroke displays on character form and meaning acquisition. J. Neurolinguist. 33, 78-95. doi: 10.1016/j.jneuroling.2014.09.001

Chen, L., Perfetti, C. A., Fang, X., and Chang, L. Y. (2021). Activation of L1 orthography in L2 word reading: constraints from language and writing system. Second Lang. Res. 37, 323-348. doi: 10.1177/0267658320927761

Cheng, H. (2006)。“关于考生团体异质程度对 HSK(初、中等)信度的影响 [On the influence of the test takers' population's degree of difference on the ElementaryIntermediate HSK's reliability]," in 汉语水平考试(HSK)研究 [HSK Research], ed. K. Zhang (Beijing: The Commercial Press), 150-184.

Chinese Language Committee (2009). Modern Chinese Common Character List (Hanyu Tongyong Zibiao). Beijing: Commercial Press.

Chung, K. K. H., Lam, C. B., and Cheung, K. C. (2018). Visuomotor integration and executive functioning are uniquely linked to Chinese word reading and writing in kindergarten children. Read. Writ. 31, 155-171. doi: 10.1007/s11145-0179779-4

Clark, A. (1997). Being There: Putting Brain, Body, and World Together Again Cambridge, MA: The MIT Press.

Cohen, J. (1988). Statistical Power Analysis for the Behavioral Sciences, 2nd Edn. Hillsdale, NJ: Lawrence Erlbaum Associates.

Cook, V., Bassetti, B., Kasai, C., Sasaki, M., and Takahashi, J. A. (2006). Do bilinguals have different concepts? The case of shape and material in Japanese L2 users of English. Int. J. Bilingual 10, 137-152. doi: 10.1177/ 13670069060100020201

Dall, J. O., Wang, Y. M., Cai, X. L., Chan, R. C. K., and Sørensen, T. A. (2021). Visual short-term memory and attention: an investigation of familiarity and stroke count in Chinese characters. J. Exp. Psychol. Learn. Mem. Cogn. 47, 282-294. doi: $10.1037 / x \operatorname{lm} 0000950$

DeLuca, V., Rothman, J., Bialystok, E., and Pliatsikas, C. (2020). Duration and extent of bilingual experience modulate neurocognitive outcomes. Neuroimage 204:116222. doi: 10.1016/j.neuroimage.2019.11 6222

Desai, R. H., Binder, J. R., Conant, L. L., and Seidenberg, M. S. (2010). Activation of sensory-motor areas in sentence comprehension. Cereb. Cortex 20, 468-478. doi: 10.1093/cercor/bhp115

Diefenbach, C., Rieger, M., Massen, C., and Prinz, W. (2013). Action-sentence compatibility: the role of action effects and timing. Front. Psychol. 4:272. doi: 10.3389/fpsyg.2013.00272

Dryer, M. S., and Haspelmath, M. (2013). The World Atlas of Language Structures Online. WALS.info. Available online at: http://wals.info (accessed July 18, 2021)

$\mathrm{Du}, \mathrm{Z}$. (2015). The Chinese Language Demystified. Newcastle upon Tyne: Cambridge Scholars Publishing.

Ehri, L. C. (2005). Learning to read words: theory, findings, and issues. Sci. Stud. Read. 9, 167-188. doi: 10.1207/s1532799xssr0902_4

Ehri, L. C. (2014). Orthographic mapping in the acquisition of sight word reading, spelling memory, and vocabulary learning. Sci. Stud. Read. 18, 5-21. doi: 10. $1080 / 10888438.2013 .819356$

Ellis, R. (2008). The Study of Second Language Acquisition, 2nd Edn. New York, NY: Oxford University Press.

Emmorey, K., McCullough, S., Mehta, S., and Grabowski, T. J. (2014). How sensory-motor systems impact the neural organization for language: direct contrasts between spoken and signed language. Front. Psychol. 5:484. doi: 10. 3389/fpsyg.2014.00484 
Enders, C. K., and Tofighi, D. (2007). Centering predictor variables in crosssectional multilevel models: a new look at an old issue. Psychol. Methods 12, 121-138. doi: 10.1037/1082-989X.12.2.121

Enfield, N. J. (2011). "Dynamics of human diversity in mainland Southeast Asia," in Dynamics of Human Diversity: The Case of Mainland Southeast Asia, ed. N. J. Enfield (Canberra, ACT: Pacific Linguistics), 1-8.

Filipović, L. (2011). Speaking and remembering in one or two languages: bilingual vs. monolingual lexicalization and memory for motion events. Int. J. Biling. 15, 466-485. doi: 10.1177/1367006911403062

Gallese, V. (2014). Bodily selves in relation: embodied simulation as secondperson perspective on intersubjectivity. Philos. Trans. R. Soc. Lond. B Biol. Sci. 369:20130177. doi: 10.1098/rstb.2013.0177

Gibjr, R. W. (2010). Metaphor interpretation as embodied simulation. Mind Lang. 21, 434-458. doi: 10.1111/j.1468-0017.2006.00285.x

Glenberg, A. M., and Gallese, V. (2012). Action-based language: a theory of language acquisition, comprehension, and production. Cortex 48, 905-922. doi: 10.1016/j.cortex.2011.04.010

Glenberg, A. M., and Robertson, D. A. (1999). Indexical understanding of instructions. Discourse Process. 28, 1-26. doi: 10.1080/01638539909545067

Glenberg, A. M., and Robertson, D. A. (2000). Symbol grounding and meaning: a comparison of high-dimensional and embodied theories of meaning. J. Mem. Lang. 43, 379-401. doi: 10.1006/jmla.2000.2714

Green, D. W., and Abutalebi, J. (2013). Language control in bilinguals: the adaptive control hypothesis. J. Cogn. Psychol. 25, 515-530. doi: 10.1080/20445911.2013. 796377

Guan, C. Q., and Fraundorf, S. H. (2020). Cross-linguistic word recognition development among Chinese children: a multilevel linear mixed-effects modeling approach. Front. Psychol. 11:544. doi: 10.3389/fpsyg.2020.00544

Guan, C. Q., Smolen, E. R., Meng, W., and Booth, J. R. (2021). Effect of handwriting on visual word recognition in Chinese bilingual children and adults. Front. Psychol. 12:628160. doi: 10.3389/fpsyg.2021.628160

Gullifer, J. W., Chai, X. J., Whitford, V., Pivneva, I., Baum, S., Klein, D., et al. (2018). Bilingual experience and resting-state brain connectivity: impacts of L2 age of acquisition and social diversity of language use on control networks. Neuropsychologia 117, 123-134. doi: 10.1016/j.neuropsychologia.2018.04.037

Gullifer, J. W., Kousaie, S., Gilbert, A. C., Grant, A., Giroud, N., Coulter, $\mathrm{K}$., et al. (2021). Bilingual language experience as a multidimensional spectrum: associations with objective and subjective language proficiency. Appl. Psycholinguist. 42, 245-278. doi: 10.1017/s0142716420000521

Hamada, M., and Koda, K. (2008). Influence of first language orthographic experience on second language decoding and word learning. Lang. Learn. 58, 1-31. doi: 10.1111/j.1467-9922.2007.00433.x

Hanban (2011). Chinesetest. cn. Available online at: http://www.chinesetest.cn/ gonewcontent.do? id=2317021 (accessed July 18, 2021).

Heck, R. H., Thomas, S. L., and Tabata, L. N. (2013). Multilevel and Longitudinal Modeling with IBM SPSS, 2nd Edn. New York, NY: Routledge.

Henning, G. H. (1973). Remembering foreign language vocabulary: acoustic and semantic parameters. Lang. Learn. 23, 185-196. doi: 10.1111/j.1467-1770.1973. tb00654.x

Hofmann, D. A., and Gavin, M. B. (1998). Centering decisions in hierarchical linear models: implications for research in organizations. J. Manage. 24, 623-641. doi: $10.1177 / 014920639802400504$

Holman, E. W., Wichmann, S., Brown, C. H., Velupillai, V., Müller, A., and Bakker, D. (2008). Explorations in automated language classification. Folia Linguist. 42, 331-354. doi: 10.1515/flin.2008.331

Hox, J. (2010). Multilevel Analysis: Techniques and Applications, 2nd Edn. New York, NY: Routledge.

Hsiao, H. S., Chang, C. S., Chen, C. J., Wu, C. H., and Lin, C. Y. (2015). The influence of Chinese character handwriting diagnosis and remedial instruction system on learners of Chinese as a foreign language. Comput. Assist. Lang. Learn. 28, 306-324. doi: 10.1080/09588221.2013.818562

Hu, Z., Zhang, J., Couto, T. A., Xu, S., Luan, P., and Yuan, Z. (2018). Optical mapping of brain activation and connectivity in occipitotemporal cortex during Chinese character recognition. Brain Topogr. 31, 1014-1028. doi: 10.1007/ s10548-018-0650-y

Huang, C. (2006). “概化理论及其在HSK测试中的应用 [Generalization theory and its application on the HSK test], " in 汉语水平考试(HSK)研究 [HSK Research], ed. K. Zhang (Beijing: The Commercial Press), 291-304.
Huang, S., Zhou, Y., Du, M., Wang, R., and Cai, Z. G. (2021b). Character amnesia in Chinese handwriting: a mega-study analysis. Lang. Sci. 85:101383. doi: 10. 1016/j.langsci.2021.101383

Huang, S., Lin, W., Xu, M., Wang, R., and Cai, Z. G. (2021a). On the tip of the pen: effects of character-level lexical variables and handwriter-level individual differences on orthographic retrieval difficulties in Chinese handwriting. Q. J. Exp. Psychol. 74, 1497-1511. doi: 10.1177/17470218211004385

Huang, X., Lin, D., Yang, Y., Xu, Y., Chen, Q., and Tanenhaus, M. K. (2020). Effects of character and word contextual diversity in Chinese beginning readers. Sci. Stud. Read. 25, 251-271. doi: 10.1080/10888438.2020.1768258

Hutchins, E. (1995). Cognition in the Wild. London: MIT Press.

Inui, T. (2006). Editorial: experimental approach to embodied cognition: editorial. Jpn. Psychol. Res. 48, 123-125. doi: 10.1111/j.1468-5884.2006.00313.x

James, K. H. (2017). The importance of handwriting experience on the development of the literate brain. Curr. Dir. Psychol. Sci. 26, 502-508. doi: $10.1177 / 0963721417709821$

James, K. H., and Atwood, T. P. (2009). The role of sensorimotor learning in the perception of letter-like forms: tracking the causes of neural specialization for letters. Cogn. Neuropsychol. 26, 91-110. doi: 10.1080/02643290802425914

Jared, D., Pei Yun Poh, R., and Paivio, A. (2013). L1 and L2 picture naming in Mandarin-English bilinguals: a test of Bilingual Dual Coding Theory. Bilingualism 16, 383-396. doi: 10.1017/S1366728912000685

Jarvis, S., and Pavlenko, A. (2008). Crosslinguistic Influence in Language and Cognition. New York, NY: Routledge.

Jeon, E. H., and Yamashita, J. (2014). L2 reading comprehension and its correlates: a meta-analysis: L2 reading and its correlates. Lang. Learn. 64, 160-212. doi: 10.1111/lang. 12034

Jiang, N., Hou, F., and Jiang, X. (2020). Analytic versus holistic recognition of Chinese words among L2 learners. Mod. Lang. J. 104, 567-580. doi: 10.1111/ modl. 12662

Jiang, X. (2003). 不同母语背景的外国学生汉字知音和知义之间关系的研究 [The relationship between knowing pronunciation and knowing meaning of Chinese characters among CSL learners]. 语言教学与研究 Lang. Teach. Linguis. Stud. 6, 51-57.

Joshi, R. M., and Aaron, P. G. (2000). The component model of reading: simple view of reading made a little more complex. Read. Psychol. 21, 85-97. doi: $10.1080 / 02702710050084428$

Joshi, R. M., and Aaron, P. G. (2012). Componential model of reading (CMR): validation studies. J. Learn. Disabil. 45, 387-390. doi: 10.1177/ 0022219411431240

Ju, Z., Zhou, Y., and delMas, R. (2021). The contributions of separate pinyin skills and oral vocabulary to Chinese word reading of U.S. Mandarin immersion third graders. Read. Writ. 34, 2439-2459. doi: 10.1007/s11145-021-10150-9

$\mathrm{Ke}, \mathrm{C}$. (1998). Effects of language background on the learning of Chinese characters among foreign language students. Foreign Lang. Ann. 31, 91-102. doi: 10.1111/ j.1944-9720.1998.tb01335.x

Ke, S., and Chan, S. D. (2017). Strategy use in L2 Chinese reading: the effect of L1 background and L2 proficiency. System 66, 27-38. doi: 10.1016/j.system.2017. 03.005

Kimchi, R., and Hadad, B. S. (2002). Influence of past experience on perceptual grouping. Psychol. Sci. 13, 41-47. doi: 10.1111/1467-9280.00407

Knell, E., and West, H. I. N. (2017). To delay or not to delay: the timing of Chinese character instruction for secondary learners. Foreign Lang. Ann. 50, 519-532. doi: $10.1111 /$ flan.12281

Koda, K. (2005a). "Learning to read across writing systems: transfer, metalinguistic awareness, and second language reading development," in Second Language Writing Systems, ed. V. J. Cook (Clevedon: Multilingual Matters), 311-334.

Koda, K. (2005b). Insights into Second Language Reading: A Cross-Linguistic Approach, 1st Edn. Stuttgart: Klett Sprachen.

Koda, K. (2007). Reading and language learning: crosslinguistic constraints on second language reading development. Lang. Learn. 57, 1-44. doi: 10.1111/ 0023-8333.101997010-i1

Koda, K. (2008). "Impacts of prior literacy experience on second language learning to read," in Learning to Read Across Languages: Cross-Linquistic Relationships in First-and Second-Language Literacy Development, eds K. Koda and A. M. Zehler (New York, NY: Routledge), 68-96.

Kuo, L. J., Kim, T. J., Yang, X., Li, H., Liu, Y., Wang, H., et al. (2015). Acquisition of Chinese characters: the effects of character properties and individual differences 
among second language learners. Front. Psychol. 6:986. doi: 10.3389/fpsyg.2015. 00986

Lakoff, G., and Johnson, M. (1980). Metaphors We Live By. Chicago, IL: University of Chicago Press.

Lakoff, G., and Johnson, M. (1999). Philosophy in the Flesh: The Embodied Mind and its Challenge to Western Thought. London: Basic Books.

Lam, S. S. Y., and McBride, C. (2018). Learning to write: the role of handwriting for Chinese spelling in kindergarten children. J. Educ. Psychol. 110, 917-930. doi: 10.1037/edu0000253

Lan, Y.-J., Chen, N.-S., Li, P., and Grant, S. (2015). Embodied cognition and language learning in virtual environments. Educ. Technol. Res. Dev. 63, 639644. doi: 10.1007/s11423-015-9401-x

Lawrence, R. L. (2012). Coming full circle: reclaiming the body. New. Dir. Adult Contin. Educ. 134, 71-78. doi: 10.1002/ace.20019

Leung, A. K. Y., Qiu, L., Ong, L., and Tam, K. P. (2011). Embodied cultural cognition: situating the study of embodied cognition in socio-cultural contexts. Soc. Personal. Psychol. Compass 5, 591-608. doi: 10.1111/j.1751-9004.2011. 00373. $\mathrm{x}$

Li, L., Li, X., and Ao, L. (2014). 汉语水平与母语背景对留学生汉字正字法意识的影响 [Influences of Chinese proficiency and native language background on Chinese orthographic awareness of foreign students].心理研究 Psychol. Res. 7, 37-42.

Li, L., Wu, X., Cheng, Y., and Nguyen, T. P. (2019). The relationship of character reading and spelling: a longitudinal study in Chinese. J. Res. Read. 42, 18-36. doi: $10.1111 / 1467-9817.12131$

Li, M. (2020). A systematic review of the research on Chinese character teaching and learning. Front. Educ. China 15, 39-72. doi: 10.1007/s11516-020-0003-y

Li, X., and Zhang, H. (2021). 母语文字背景对汉字学习态度的影响——基于二分法和三分法的 对比研究 [The influence of L1 background on CSL learners' attitudes toward learning Chinese characters-a comparative study of dichotomous and trichotomous approaches].汉字文化 Sinogram Cult. 141-146. doi: 10.14014/j.cnki.cn11-2597/g2.2021.09.03

Liao, C. H., Georgiou, G. K., and Parrila, R. (2008). Rapid naming speed and Chinese character recognition. Read. Writ. 21, 231-253. doi: 10.1007/s11145007-9071-0

Lin, C.-H., and Collins, P. (2012). The effects of L1 and orthographic regularity and consistency in naming Chinese characters. Read. Writ. 25, 1747-1767. doi: 10.1007/s11145-011-9340-9

Lindsay, S., and Gaskell, M. G. (2010). A complementary systems account of word learning in L1 and L2: learning words in L1 and L2. Lang. Learn. 60, 45-63. doi: 10.1111/j.1467-9922.2010.00600.x

Liu, C., Tardif, T., Mai, X., Gehring, W. J., Simms, N., and Luo, Y.-J. (2010). What's in a name? Brain activity reveals categorization processes differ across languages. Hum. Brain Mapp. 31, 1786-1801. doi: 10.1002/hbm.20974

Liu, P. D., and McBride-Chang, C. (2010). What is morphological awareness? Tapping lexical compounding awareness in Chinese third graders. J. Educ. Psychol. 102, 62-73. doi: 10.1037/a0016933

Loh, E. K. Y., Liao, X., and Leung, S. O. (2018). Acquisition of orthographic knowledge: developmental difference among learners with Chinese as a second language (CSL). System 74, 206-216. doi: 10.1016/j.system.2018.03.018

Longcamp, M., Anton, J. L., Roth, M., and Velay, J. L. (2003). Visual presentation of single letters activates a premotor area involved in writing. Neuroimage 19, 1492-1500. doi: 10.1016/s1053-8119(03)00088-0

Longcamp, M., Anton, J. L., Roth, M., and Velay, J. L. (2005). Premotor activations in response to visually presented single letters depend on the hand used to write: a study on left-handers. Neuropsychologia 43, 1801-1809. doi: 10.1016/ j.neuropsychologia.2005.01.020

Longcamp, M., Tanskanen, T., and Hari, R. (2006). The imprint of action: motor cortex involvement in visual perception of handwritten letters. Neuroimage 33, 681-688. doi: 10.1016/j.neuroimage.2006.06.042

Macedonia, M. (2014). Bringing back the body into the mind: gestures enhance word learning in foreign language. Front. Psychol. 5:1467. doi: 10.3389/fpsyg. 2014.01467

Matisoff, J. A. (1973). “Tonogenesis in Southeast Asia," in Southern California Occasional Papers in Linguistics, ed. L. M. Hyman (Los Angeles, CA: University of Southern California Press), 72-95.

Matisoff, J. A. (1986). Hearts and minds in South-East Asian languages and English: an essay in the comparative lexical semantics of psycho-collocations. Cah. Linguist. Asie Orient. 15, 5-57. doi: 10.1163/19606028-90000013
Matisoff, J. A. (2001). "Genetic versus contact relationship: prosodic diffusability in Southeast Asian languages," in Areal Diffusion and Genetic Inheritance: Problems in Comparative Linguistics, eds A. Y. Aikhenvald and R. M. W. Dixon (Oxford: Oxford University Press), 291-327.

McBride, C. A. (2016). Is Chinese special? Four aspects of Chinese literacy acquisition that might distinguish learning Chinese from learning alphabetic orthographies. Educ. Psychol. Rev. 28, 523-549. doi: 10.1007/s10648-0159318-2

McBride-Chang, C., Bialystok, E., Chong, K. K. Y., and Li, Y. (2004). Levels of phonological awareness in three cultures. J. Exp. Child Psychol. 89, 93-111. doi: 10.1016/j.jecp.2004.05.001

McNaughton, W., and Ying, L. (1999). Reading and Writing Chinese: Guide to the Chinese Writing System, 2nd Edn. NewYork, NY: Tuttle Publishing.

Melby-Lervåg, M., and Lervåg, A. (2011). Cross-linguistic transfer of oral language, decoding, phonological awareness and reading comprehension: a meta-analysis of the correlational evidence. J. Res. Read. 34, 114-135. doi: 10.1111/j.14679817.2010.01477.x

Meyer, F. K. (2014). Language Proficiency Testing for Chinese as A Foreign Language: An Argument-Based Approach for Validating the Hanyu Shuiping Kaoshi (HSK). Pieterlen: Peter Lang AG.

Nagy, W. E., Kuo-Kealoha, A., Xinchun, W., Wenling, L., Anderson, R. C., and Xi, C. (2002). "The role of morphological awareness in learning to read Chinese," in Chinese Children's Reading Acquisition, eds L. Wenling, J. S. Gaffney, and J. L. Packard (Boston, MA: Springer US), 59-86. doi: 10.1007/978-1-4615-0859-5_4

Odlin, T. (1989). Cambridge Applied Linguistics: Language Transfer: CrossLinguistic Influence in Language Learning. Cambridge: Cambridge University Press.

Pae, H. K. (2020). "Chinese, Japanese, and Korean writing systems: all East-Asian but different scripts," in Script Effects as the Hidden Drive of the Mind, Cognition, and Culture, ed. H. K. Pae (Cham: Springer International Publishing), doi: 10.1007/978-3-030-55152-0_5

Papesh, M. H. (2015). Just out of reach: on the reliability of the actionsentence compatibility effect. J. Exp. Psychol. Gen. 144, e116-e141. doi: 10.1037/ xge0000125

Park, H. I. (2020). How do Korean-English bilinguals speak and think about motion events? Evidence from verbal and non-verbal tasks. Bilingualism 23, 483-499. doi: 10.1017/S1366728918001074

Pavlenko, A., and Driagina, V. (2007). Russian emotion vocabulary in American learners? Narratives. Mod. Lang. J. 91, 213-234. doi: 10.1111/j.1540-4781.2007. 00541.x

Pavlenko, A., and Malt, B. C. (2011). Kitchen Russian: cross-linguistic differences and first-language object naming by Russian-English bilinguals. Biling Camb. Engl. 14, 19-45. doi: 10.1017/s136672891000026x

Perfetti, C. A., and Hart, L. (2002). “The lexical quality hypothesis," in Precursors of Functional Literacy, eds L. Vehoeven, C. Elbro, and P. Reitsma (Amsterdam: John Benjamins Publishing Company), 189-213. doi: 10.1075/swll.11. 14per

Phakiti, A. (2003). A closer look at gender and strategy use in L2 reading: language learning. Lang. Learn. 53, 649-702. doi: 10.1046/j.1467-9922.2003.00239.x

Piaget, J. (1976). "Piaget's theory," in Piaget and His School, eds B. Inhelder, H. Chipman, and C. Zwingmann (Berlin: Springer), 11-23.

Qian, K., Owen, N., and Bax, S. (2018). Researching mobile-assisted Chinesecharacter learning strategies among adult distance learners. Innov. Lang. Learn. Teach. 12, 56-71. doi: 10.1080/17501229.2018.1418633

Quinn, N. (1987). "Convergent evidence for a cultural model of American marriage," in Cultural Models in Language and Thought, eds D. Holland and N. Quinn (Cambridge: Cambridge University Press), 173-192. doi: 10.1017/ cbo9780511607660.008

Raudenbush, S. W., and Bryk, A. S. (2002). Hierarchical Linear Models: Applications and Data Analysis Methods. Thousand Oaks, CA: SAGE Publications, Inc.

Raudenbush, S. W., Bryk, A. S., Cheong, Y. F., Congdon, R. T., and du Toit, M. (2006). HLM 6: Hierarchical Linear and Nonlinear Modeling. Linconwood, IL: Scientific Software International, Inc.

Rohrer, T. (2007). “The body in space: dimensions of embodiment," in Body, Language and Mind, eds T. Ziemke, J. Zlatev, and R. M. Frank (Berlin: de Gruyter Mouton), 339-378.

Shapiro, L. (2007). The embodied cognition research programme. Philos. Compass 2, 338-346. doi: 10.1111/j.1747-9991.2007.00064.x 
Sharwood Smith, M., and Kellerman, E. (1986). "Cross-linguistic influence in second language: an intro-duction," in Cross-Linguistic Influence in Second Language Acquisition, eds E. Kellerman and M. Sharwood Smith (Oxford: Pergamon), 1-9.

Shen, H. H. (2005). An investigation of Chinese-character learning strategies among non-native speakers of Chinese. System 33, 49-68. doi: 10.1016/j.system. 2004.11.001

Shen, H. H. (2010). "Analysis of radical knowledge development among beginning CFL learners," in Research Among Learners of Chinese as a Foreign Language, eds M. E. Everson and H. H. Shen (Honolulu, HI: National Foreign Language Resource Center), 45-66.

Shen, H. H., and Ke, C. (2007). Radical awareness and word acquisition among nonnative learners of Chinese. Mod. Lang. J. 91, 97-111. doi: 10.1111/j.15404781.2007.00511.x

Siok, W. T., and Fletcher, P. (2001). The role of phonological awareness and visualorthographic skills in Chinese reading acquisition. Dev. Psychol. 37, 886-899. doi: 10.1037//0012-1649.37.6.886

Slepian, M. L., and Ambady, N. (2014). Simulating sensorimotor metaphors: novel metaphors influence sensory judgments. Cognition 130, 309-314. doi: 10.1016/ j.cognition.2013.11.006

Smithson, L., and Nicoladis, E. (2013). Verbal memory resources predict iconic gesture use among monolinguals and bilinguals. Bilingualism 16, 934-944. doi: $10.1017 /$ S1366728913000175

Spackman, J. S., and Yanchar, S. C. (2014). Embodied cognition, representationalism, and mechanism: a review and analysis. J. Theory Soc. Behav. 44, 46-79. doi: 10.1111/jtsb.12028

Stanovich, K. E. (2000). Progress in Understanding Reading: Scientific Foundations and New Frontiers. New York, NY: Guilford Publications.

Strati, A. (2007). Sensible knowledge and practice-based learning. Manag. Learn. 38, 61-77. doi: 10.1177/1350507607073023

Streeck, J., Goodwin, C., and LeBaron, C. (2011). Embodied Interaction: Language and Body in the Material World. Cambridge, TAS: Cambridge University Press.

Sung, K. Y., and Wu, H. P. (2011). Factors influencing the learning of Chinese characters. Int. J. Biling. Educ. Biling. 14, 683-700. doi: 10.1080/13670050.2011. 571658

Swain, M. (2000). "The output hypothesis and beyond: mediating acquisition through collaborative dialogue," in Sociocultural Theory and Second Language Learning, ed. J. Lantolf (Oxford: Oxford University Press), 97-114.

Tabachnick, B. G., and Fidell, L. S. (2013). Using Multivariate Statistics: Pearson New International Edition, 6th Edn. London: Pearson Education.

Tan, L. H., Laird, A. R., Li, K., and Fox, P. T. (2005a). Neuroanatomical correlates of phonological processing of Chinese characters and alphabetic words: a meta-analysis. Hum. Brain Mapp. 25, 83-91. doi: 10.1002/hbm.20134.s

Tan, L. H., Spinks, J. A., Eden, G. F., Perfetti, C. A., and Siok, W. T. (2005b). Reading depends on writing, in Chinese. Proc. Natl. Acad. Sci. U.S.A. 102, 8781-8785. doi: 10.1073/pnas.0503523102

Tan, L. H., Liu, H. L., Perfetti, C. A., Spinks, J. A., Fox, P. T., and Gao, J. H. (2001). The neural system underlying Chinese logograph reading. Neuroimage 13, 836-846. doi: 10.1006/nimg.2001.0749

Tang, M., and Chan, S. D. (2021). Effects of word semantic transparency, context length, and L1 background on CSL learners' incidental learning of word meanings in passage-level reading. J. Psycholinguist. Res. doi: 10.1007/s10936021-09786-Z

Teng, Y. (2017). "Hanyu Shuiping Kaoshi (HSK): past, present, and future," in Chinese Language Learning Sciences, eds D. Zhang and C. H. Lin (Singapore: Springer Singapore), 3-19. doi: 10.1007/978-981-10-4089-4_1

Tiv, M., O’Regan, E., and Titone, D. (2020). Bilingual social cognition: investigating the relationship between bilingual language experience and mentalizing. PsyArXiv [Preprint]. doi: 10.31234/osf.io/nbsxh

Tong, X., Kwan, J. L. Y., Wong, D. W. M., Lee, S. M. K., and Yip, J. H. Y. (2016). Toward a dynamic interactive model of non-native Chinese character processing. J. Educ. Psychol. 108, 680-693. doi: 10.1037/edu0000083

Tong, X., Leung, W. W. S., and Tong, X. (2019). Visual statistical learning and orthographic awareness in Chinese children with and without developmental dyslexia. Res. Dev. Disabil. 92:103443. doi: 10.1016/j.ridd.2019.10 3443

Tong, X., and McBride-Chang, C. (2010). Developmental models of learning to read Chinese words. Dev. Psychol. 46, 1662-1676. doi: 10.1037/a0020611
Tong, X., and Yip, J. H. Y. (2015). Cracking the Chinese character: radical sensitivity in learners of Chinese as a foreign language and its relationship to Chinese word reading. Read. Writ. 28, 159-181. doi: 10.1007/s11145-0149519-y

Tso, R. V. Y., Au, T. K., and Hsiao, J. H. (2011). "The influence of writing experiences on holistic processing in Chinese character recognition," in Proceedings of the 33rd Annual Conference of the Cognitive Science Society, eds L. Carlson, C. Hoelscher, and T. F. Shipley (Austin, TX: Cognitive Science Society), 1442-1447.

Van der Slik, F. W. P., van Hout, R. W. N. M., and Schepens, J. J. (2015). The gender gap in second language acquisition: gender differences in the acquisition of Dutch among immigrants from 88 countries with 49 mother tongues. PLoS One 10:e0142056. doi: 10.1371/journal.pone.0142056

Vilas, M. G., Santilli, M., Mikulan, E., Adolfi, F., Martorell Caro, M., Manes, F., et al. (2019). Reading Shakespearean tropes in a foreign tongue: age of L2 acquisition modulates neural responses to functional shifts. Neuropsychologia 124, 79-86. doi: 10.1016/j.neuropsychologia.2019.01.007

Vygotsky, L. S. (1978). Mind in Society: The Development of Higher Mental Process. Cambridge, MA: Harvard University Press.

Wang, M., Perfetti, C. A., and Liu, Y. (2003). Alphabetic readers quickly acquire orthographic structure in learning to read Chinese. Sci. Stud. Read. 7, 183-208. doi: 10.1207/s1532799xssr0702_4

Wang, R., Huang, S., Zhou, Y., and Cai, Z. G. (2020). Chinese character handwriting: a large-scale behavioral study and a database. Behav. Res. Methods 52, 82-96. doi: 10.3758/s13428-019-01206-4

Wang, X., Ma, X., Tao, Y., Tao, Y., and Li, H. (2018). How semantic radicals in Chinese characters facilitate hierarchical category-based induction. Sci. Rep. 8:5577. doi: 10.1038/s41598-018-23281-x

Wang, Y., McBride-Chang, C., and Chan, S. F. (2014). Correlates of Chinese kindergarteners' word reading and writing: the unique role of copying skills? Read. Writ. 27, 1281-1302. doi: 10.1007/s11145-013-9486-8

Wang, Y., and Wei, L. (2019). Cognitive restructuring in the bilingual mind: motion event construal in early Cantonese-English bilinguals. Lang. Cogn. 11, 527-554. doi: 10.1017/langcog.2019.31

Wang, Y., Yin, L., and McBride, C. (2015). Unique predictors of early reading and writing: a one-year longitudinal study of Chinese kindergarteners. Early Child. Res. Q. 32, 51-59. doi: 10.1016/j.ecresq.2015.02.004

Wichmann, S., Holman, E. W., and Brown, C. H. (2020). The ASJP Database. Available online at: https://asjp.clld.org/ (accessed September 3, 2021).

Wierzbicka, A. (1989). Soul and mind: linguistic evidence for ethnopsychology and cultural history. Am. Anthropol. 91, 41-58. doi: 10.1525/aa.1989.91.1.02a00030

Wierzbicka, A. (1992). Semantics, Culture, and Cognition: Universal Human Concepts in Culture-Specific Configurations. New York, NY: Oxford University Press.

Wilson, A. D., and Golonka, S. (2013). Embodied cognition is not what you think it is. Front. Psychol. 4:58. doi: 10.3389/fpsyg.2013.00058

Wong, Y. K. (2017). The role of radical awareness in Chinese-as-a-second-language learners' Chinese character reading development. Lang. Aware. 26, 211-225. doi: 10.1080/09658416.2017.1400039

Wong, Y. K. (2018). Exploring the reading-writing relationship in young Chinese language learners' sentence writing. Read. Writ. 31, 945-964. doi: 10.1007/ s11145-018-9820-2

Xiao, H., Xu, C., and Rusamy, H. (2020). Pinyin spelling promotes reading abilities of adolescents learning Chinese as a foreign language: evidence from mediation models. Front. Psychol. 11:596680. doi: 10.3389/fpsyg.2020.596680

$\mathrm{Xu}$, C. (2007). 外国留学生汉字分解水平的发展 [The development of foreign learners' process to decompose Chinese characters].世界汉语教学 Chin. Teach. World $16-28+2$.

Xu, Y., Chang, L. Y., Zhang, J., and Perfetti, C. A. (2013). Reading, writing, and animation in character learning in Chinese as a foreign language. Foreign Lang. Ann. 46, 423-444. doi: 10.1111/flan. 12040

Xu, Y. L. (1992). 对比语言学概论 [An Introduction to Contrastive Linguistics]. Shanghai: Shanghai Foreign Language Education Press.

Ye, L. (2013). Shall we delay teaching characters in teaching Chinese as a foreign language? Foreign Lang. Ann. 46, 610-627. doi: 10.1111/flan.12049

Ye, Y., Tong, C. K. Y., McBride, C., Yin, L., and Tse, C. Y. (2021). Concurrent and longitudinal predictors of beginning writing in Chinese: the unique role of copying skills. Read. Writ. 34, 2417-2437. doi: 10.1007/s11145-021-10149-2 
Yeh, S. L., Li, J. L., Takeuchi, T., Sun, V., and Liu, W. R. (2003). The role of learning experience on the perceptual organization of Chinese characters. Vis. Cogn. 10, 729-764. doi: 10.1080/13506280344000077

Yin, Y., Cai, X., Ouyang, M., and Zhang, Q. (2020). The N200 enhancement effect in reading Chinese is modulated by actual writing. Neuropsychologia 142:107462. doi: 10.1016/j.neuropsychologia.2020.107462

Yin, Y., and Zhang, Q. (2021). Chinese characters are read using not only visual but also writing motor information. Psychophysiology 58, e13696. doi: 10.1111/ psyp.13696

Yu, N. (2009). The Chinese HEART in A Cognitive Perspective: Culture, Body, and Language. Berlin: De Gruyter Mouton.

Zhai, M., and Fischer-Baum, S. (2019). Exploring the effects of knowledge of writing on reading Chinese characters in skilled readers. J. Exp. Psychol. Learn. Mem. Cogn. 45, 724-731. doi: 10.1037/xlm0000604

Zhang, B. (2020). Rethinking the Sinosphere: Poetics, Aesthetics, and Identity Formation, eds N. Qian and R. J. Smith (Youngstown, OH: Cambria Press).

Zhang, D., Lin, C. H., Zhang, Y., and Choi, Y. (2019). Pinyin or no pinyin: does access to word pronunciation matter in the assessment of Chinese learners' vocabulary knowledge? Lang. Learn. J. 47, 344-353. doi: 10.1080/09571736. 2017.1289237

Zhang, H. (2014). A review of stroke order in Hanzi handwriting. Lang. Learn. High. Educ. 4, 423-440. doi: 10.1515/cercles-2014-0022

Zhang, H., and Roberts, L. (2019). The role of phonological awareness and phonetic radical awareness in acquiring Chinese literacy skills in learners of Chinese as a second language. System 81, 163-178. doi: 10.1016/j.system.2019.02.007

Zhang, H., and Roberts, L. (2021a). A comparison of Pinyin invented spelling and oddity test in measuring phonological awareness in L2 learners of Chinese. J. Psycholinguist. Res. 50, 375-396. doi: 10.1007/s10936-020-09700-z

Zhang, H., and Roberts, L. (2021b). The influence of L1 script directionality and L2 proficiency on Hanzi learning among Arabic and English learners of L2 Chinese. IRAL Int. Rev. Appl. Linguist. Lang. Teach. doi: 10.1515/iral-2018. 0330

Zhang, H., Su, I. F., Chen, F., Ng, M. L., Wang, L., and Yan, N. (2020). The time course of orthographic and semantic activation in Chinese character recognition: evidence from an ERP study. Lang. Cogn. Neurosci. 35, 292-309. doi: 10.1080/23273798.2019.1652762

Zhang, J., Li, H., Liu, Y., and Chen, Y. (2020). Orthographic facilitation in oral vocabulary learning: effects of language backgrounds and orthographic type. Read. Writ. 33, 187-206. doi: 10.1007/s11145-019-09955-6

Zhang, J. J. (2016). 东南亚国家华裔、非华裔学生汉字正字法意识的对比研究 [A comparative study of Chinese character orthographic awareness of overseas learners with Chinese origin and non-Chinese origin in Southeast Asia].
华文教学与研究 TCSOL Stud. 17-26. doi: 10.16131/j.cnki.cn44-1669/g4.20160526. 003

Zhang, J. Q. (2008), 印尼华裔留学生汉字正字法意识的形成与发展 [The formation and development of Chinese orthographic awareness of learners of Chinese Indonesians]. Appl. Linguist. 2, 116-122. doi: 10.16499/j.cnki.1003-5397.2008. 02.002

Zhang, Q., and Reilly, R. G. (2015). "Writing to read: the case of Chinese," in Proceedings of the 29th Pacific Asia Conference on Language, Information and Computation, PACLIC, Shanghai, 345-354.

Zhou, W., Kwok, V. P. Y., Su, M., Luo, J., and Tan, L. H. (2020). Children's neurodevelopment of reading is affected by China's language input system in the information era. NPJ Sci. Learn. 5:3. doi: 10.1038/s41539-020-0062-0

Zimmer, H. D., and Fischer, B. (2020). Visual working memory of Chinese characters and expertise: the expert's memory advantage is based on long-term knowledge of visual word forms. Front. Psychol. 11:516. doi: 10.3389/fpsyg. 2020.00516

Zwaan, R. A. (2004). "The immersed experiencer: toward an embodied theory of language comprehension," in The Psychology of Learning and Motivation, ed. B. H. Ross (New York, NY: Academic Press), 35-62.

Zwaan, R. A. (2016). Situation models, mental simulations, and abstract concepts in discourse comprehension. Psychon. Bull. Rev. 23, 1028-1034. doi: 10.3758/ s13423-015-0864-x

Zwaan, R. A., and Taylor, L. J. (2006). Seeing, acting, understanding: motor resonance in language comprehension. J. Exp. Psychol. Gen. 135, 1-11. doi: 10.1037/0096-3445.135.1.1

Conflict of Interest: The authors declare that the research was conducted in the absence of any commercial or financial relationships that could be construed as a potential conflict of interest.

Publisher's Note: All claims expressed in this article are solely those of the authors and do not necessarily represent those of their affiliated organizations, or those of the publisher, the editors and the reviewers. Any product that may be evaluated in this article, or claim that may be made by its manufacturer, is not guaranteed or endorsed by the publisher.

Copyright (c) 2022 Chai and Ma. This is an open-access article distributed under the terms of the Creative Commons Attribution License (CC BY). The use, distribution or reproduction in other forums is permitted, provided the original author(s) and the copyright owner(s) are credited and that the original publication in this journal is cited, in accordance with accepted academic practice. No use, distribution or reproduction is permitted which does not comply with these terms. 